\title{
Using PCM in Two Proposed Residential Buildings in Christchurch, New Zealand
}

\author{
Erik Schmerse, Charles A. Ikutegbe (D), Amar Auckaili (D) and Mohammed M. Farid *(D) \\ Department of Chemical \& Materials Engineering, University of Auckland, Auckland 1010, New Zealand; \\ akhu003@aucklanduni.ac.nz (E.S.); ciku619@aucklanduni.ac.nz (C.A.I.); a.auckaili@auckland.ac.nz (A.A.) \\ * Correspondence: m.farid@auckland.ac.nz; Tel.: +64-93-737-599; Fax: +64-93-737-463
}

Received: 30 September 2020; Accepted: 16 November 2020; Published: 18 November 2020

\begin{abstract}
A characteristic feature of lightweight constructions is their low thermal mass which causes high internal temperature fluctuations that require high heating and cooling demand throughout the year. Phase change materials (PCMs) are effective in providing thermal inertia to low-thermal-mass buildings. This paper aims to analyse the thermal behaviour of two proposed lightweight buildings designed for homeless people and to investigate the potential benefit achievable through the use of different types of PCM in the temperate climatic conditions of Christchurch, New Zealand. For this purpose, over 300 numerical simulations were conducted using DesignBuilder ${ }^{\circledR}$ simulation software. The bulk of the simulations were carried out under the assumption that the whole opaque building envelope is equipped with PCM. The results showed significant energy saving and comfort enhancement through the application of PCMs. The integration of PCM in single-structure components led to substantial energy savings between $19 \%$ and $27 \%$ annually. However, occupant behaviour in terms of ventilation habits, occupancy of zones, etc. remains one of the biggest challenges in any simulation work due to insufficient data.
\end{abstract}

Keywords: structure component; occupant behaviour; energy savings; lightweight building; comfort enhancement

\section{Introduction}

Buildings are necessary energy sinks and constitute one of the leading sectors of energy consumption globally. Putting this into proper perspective, buildings in the temperate and subtropical countries, such as in Europe, North America, and Asia, account for nearly $40 \%$ of the final energy consumed with a similar global warming potential due to carbon dioxide release [1]. On the other hand, China and India, with populations reaching 1.4 and 1.3 billion, respectively, have about $45 \%$ and $30 \%$ of their population living in cities. According to the international energy agency (IEA) report on energy outlook for developed and developing nations, these figures are expected to keep increasing in the next decade [2].

New Zealand, with a growing population of over 4.7 million people, positioned between the Antarctica and tropics ( $34^{\circ}-47^{\circ}$ latitude south), is also a culprit regarding the high energy use of buildings [3]. The location of the country is the reason for the intense fluctuations in weather conditions from a mild winter North Island to a harsh and chilled winter South Island similar to conditions in Europe. This calls for serious concerns, especially on the South Island, where Christchurch is one of the worst affected. Furthermore, the 2011 earthquake resulted in massive destruction of over 100,000 residential houses with $10 \%$ of those homes irredeemable [4]. The situation calls for a pragmatic reconstruction of the city, which is expected to take several years.

Over the years, the different building interventions witnessed are an indication of the importance of building construction to our development. The building envelope provides comfort and protection 
from unfavourable conditions caused by wind, sun, and cold or hot extreme temperatures. The various energy flows within and outside of buildings suggest that they are thermodynamically complex envelopes. Under normal conditions, the inside of a building should provide warmth and shield occupants from the effects of harsh weather conditions to guarantee a feeling of wellbeing. However, this has not been the case in colder or hotter climates due to inefficient code-complying dwellings [5]. The use of energy-efficient measures in building holds the potential to cut down the energy demand of buildings. Many researchers have considered materials that expeditiously regulate the interplay between the indoor and outdoor energy flows by storing energy temporarily for future use.

The study of phase change materials (PCMs) and their use as latent heat storage in different applications is gaining attention [6-8]. PCMs in building components can improve the thermal inertia by storing the excess heat in the building during the day time and later releasing the stored heat at night to the indoor environment when there is a drop in temperatures below the melting point of the PCM. According to [1], the selection of PCMs for building application is expected to satisfy the following criteria: high thermal conductivity $(K)$, high latent heat of fusion, a melting temperature range that fits the application, stable chemical and physical properties, and availability at a low cost.

As remarked by Hadorn [9], PCMs are divided into three groups: organic, inorganic, and eutectics compounds. Details of this division were widely reported in $[7,10]$. However, researchers have further classified PCM according to their phase transition state [11,12], e.g., solid-liquid PCM, solid-solid PCM, and liquid-gas PCM. Organic PCMs are known to exhibit excellent properties for building use [12]. They melt congruently and do not experience phase segregation. Furthermore, they are usually safe and nonreactive, while they have a moderate latent heat of fusion and self-nucleating properties. Phase segregation and supercooling are problems associated with the use of inorganic PCMs [13]. Some organic PCMs display better thermal stability after numerous thermal cycles than inorganic PCMs [14]. PCMs which are less stable can experience a shift in their melting range after multiple cycles, which makes them unsuitable for passive use in residential applications. As a result, this study focuses on organic PCMs.

The systematic application of PCMs to buildings for energy and cost savings has been published [15-19]. Among these studies, Barzin et al. [16] showed how PCMs could be applied to underfloor electric heating systems, achieving significant energy savings. The study presented in [15] investigated the potential of a thermally activated ceiling panel and reported that the potential of the newly developed ceiling system was able to abate and regulate the excessive heat emanating from the ceiling of an office building. Kuznik et al. [19] performed experiments to study the impregnation of PCMs into different construction materials. Other areas of PCM application in buildings include wallboards [20,21], floors, and ceilings for passive solar heating [22]. In [19], the energy equivalence of an organic-based PCM was compared with that of concrete. In the study, a $5 \mathrm{~mm}$ thick PCM plasterboard having $60 \mathrm{wt} . \%$ microencapsulated paraffin with a melting point temperature of $22{ }^{\circ} \mathrm{C}$ stored an amount of thermal energy equivalent to $80 \mathrm{~mm}$ thick concrete.

Several modelling and numerical simulation involving PCM in building components have been undertaken to optimise energy performance in buildings [23-25]. Na Zhu et al. [23] presented a summary of some studies that employed the use of experimental, numerical, and simulation approaches to investigate the thermal performance and dynamic characteristics of PCM-enhanced buildings. They highlighted the benefit that PCMs provide in terms of free cooling and peak load shifting. In a similar vein, [19] carried out an experimental and numerical investigation of microencapsulated PCM-perforated panels to check their performance. From their studies, results showed that the perforated panels provided an augmentation in the heat absorbed and released. In another study, Diarce et al. [24] applied the use of computational simulations to study a ventilated active façade with PCMs. The thermal behaviour of the façade was shown to compare favourably with different traditional construction systems.

According to findings from various technical studies reviewed on PCM-enhanced buildings, the annual energy savings can easily reach up to $38 \%$ in temperate climates. However, the studies were 
focused on the performance of a single-zone unit; hence, the results were not readily transferable to multi-zone buildings. Only a few studies $[26,27]$ were found to have assessed the performance of PCM in complex constructions. Furthermore, none of these studies investigated the thermal performance of lightweight PCM-enhanced buildings considered here and in climate conditions such as those prevailing in the Christchurch region. As such, the objective of the present study was to investigate the thermal inertia and energy performance of two lightweight PCM-enhanced buildings, the first being a single-zone unit and the second being a multi-zone (i.e., with internal walls) complex envelope. The choice of lightweight building materials was due to their low cost, flexibility, and ease of use in architecture design. However, the low thermal mass of such buildings usually results in large temperature fluctuations throughout the day and increased heating and cooling loads. For this reason, the application of PCM and its effect on the thermal performance of the proposed building designs were studied in this work using DesignBuilder ${ }^{\circledR}$.

\section{Methodology}

\subsection{Software Description}

This section is devoted to the description of the main procedure adapted for the development of this study. The two buildings studied in this work were modelled with Designbuilder ${ }^{\circledR}$ (DB) for dynamic comparison. One of the essential features of the programme is the provision and use of real hourly weather data in the simulations on the basis of a variety of cities all over the world [28]. Thus, the user can assess the performance of the building under actual operating conditions. Moreover, the complex interactions inside a building result in a highly nonlinear mass and energy balances which become time-consuming and cumbersome to attempt solving the problem using numerical formulations [24,29]. The heating and cooling loads were calculated according to the ASHRAE-approved "Heat Balance" method, implemented in EnergyPlus [30]. The ASHRAE Standard 55-2004 was used for the determination of the discomfort hours which were used in this work and represented "the time when the zone humidity and operative temperature are not in the ASHRAE 55 summer or winter clothes region" [31].

The present study is part of a proposed social housing project in Christchurch (New Zealand), which intends to provide simple housing for residents who would otherwise have to live on the streets. The annual weather data for the Christchurch region is presented in Figure A1 (Appendix A). The average monthly wind speed ranges between 2 and $4 \mathrm{~m} / \mathrm{s}$ with an annual wind speed of $3 \mathrm{~m} / \mathrm{s}$. June to August are the coldest months of the year, while December to February are the hottest months. As shown in Figure A1, the average daytime high outdoor temperature in the summer is within $21-23^{\circ} \mathrm{C}$, while that in the winter is between 11 and $13{ }^{\circ} \mathrm{C}$. The simulations considered multiple internal heat gains from occupants, equipment, etc. and were performed using real weather data. The simulation study provided a comprehensive first estimation of the benefits achievable through the application of PCMs for two specific building designs, before employing PCMs in these buildings. For the setting up of the simulation models, architectural plans and specifications regarding the construction materials were received from the executing contractor, and they are presented in Figures 1 and 2, respectively, for the double-unit and studio-unit houses. 


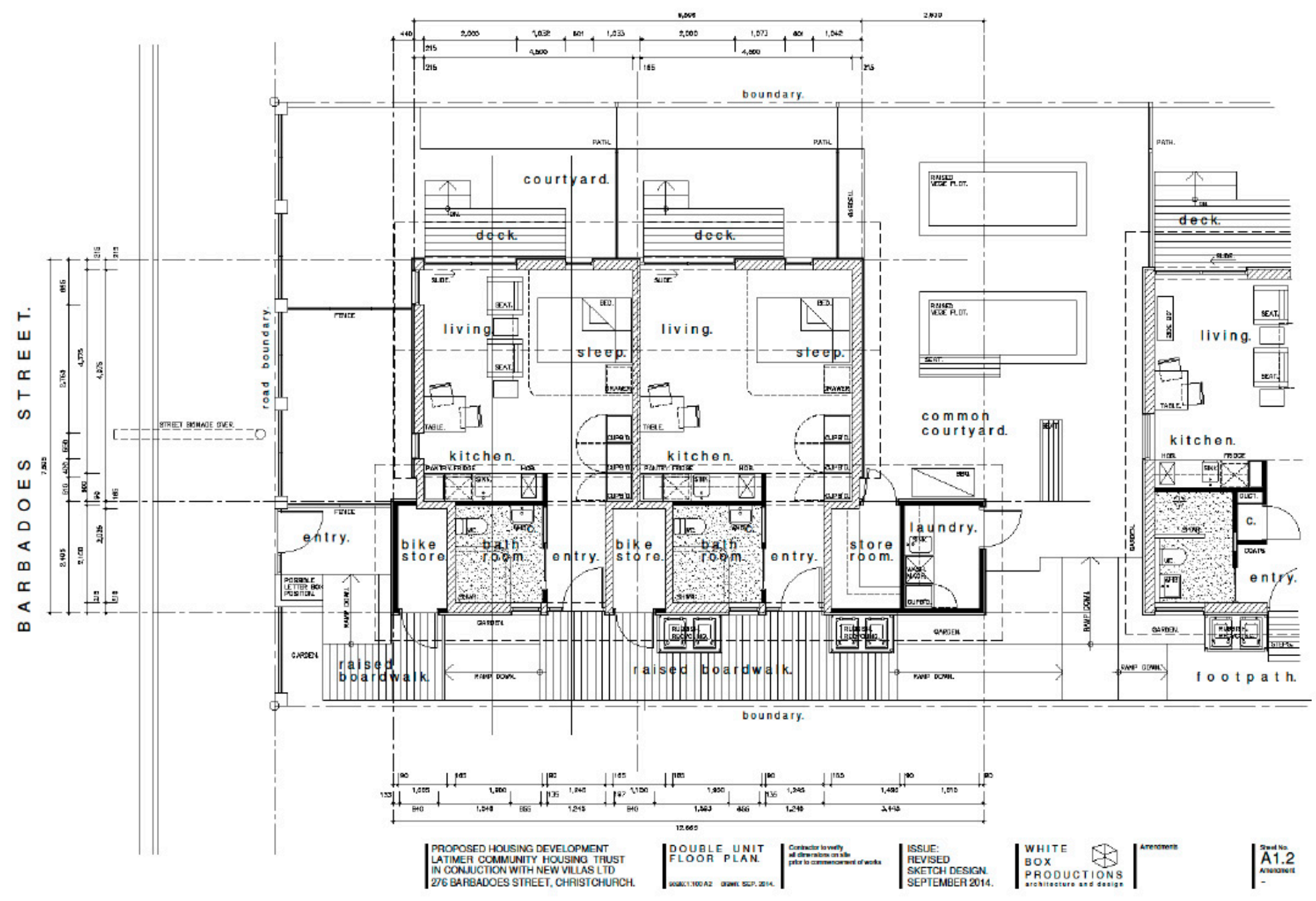

Figure 1. Plan of the model lightweight building A (double-unit house). 


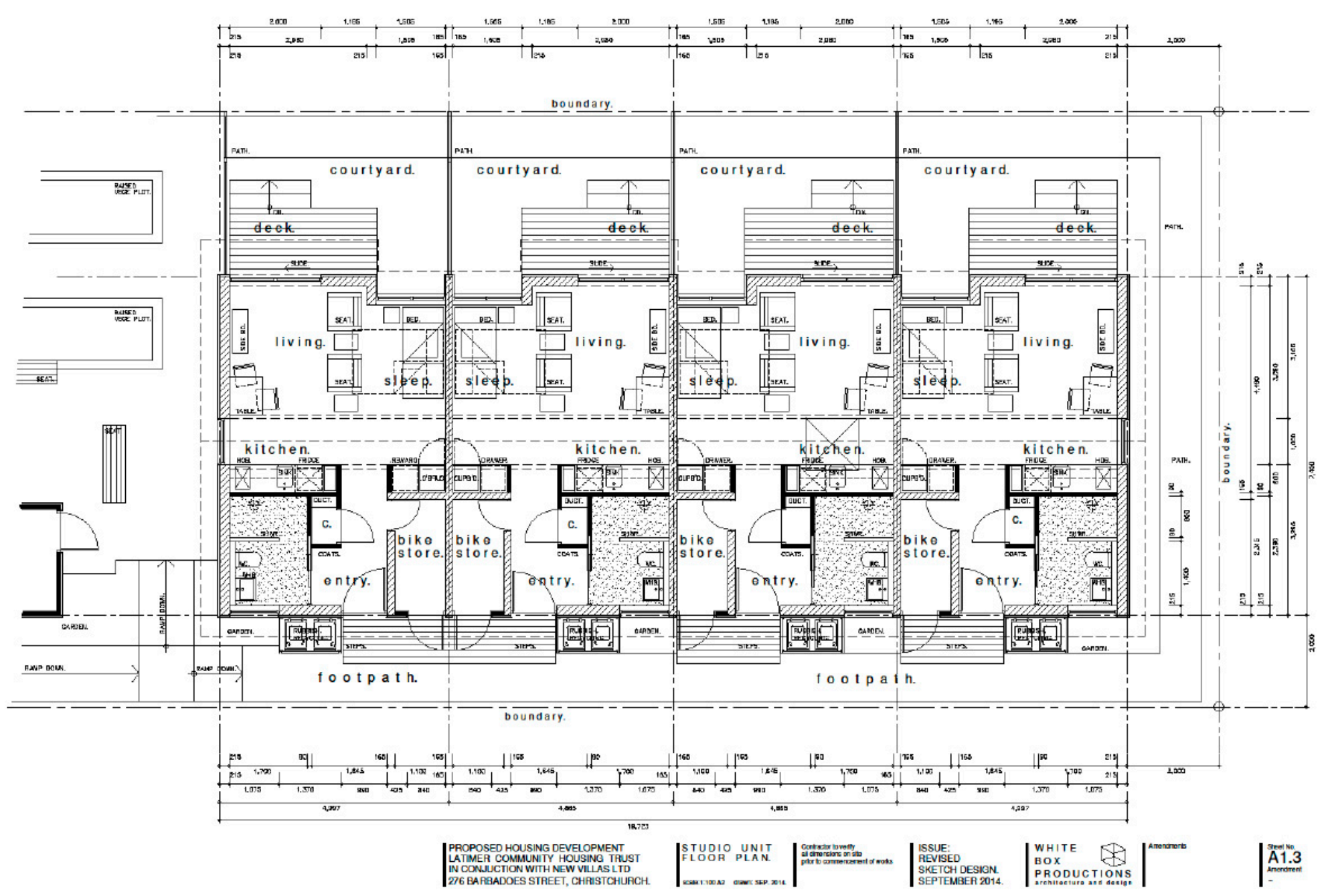

Figure 2. Plan of the model lightweight building B (studio-unit house). 


\subsection{Zone Schedule}

The schedule type for each room space (zone) and other room-based schedules are listed in Table 1, and their various schedules are defined in Figure 3. Table 1 shows the occupancy, shading control, mechanical and natural ventilation, and heating schedule type for the two buildings under study. Consider row 1 of Table 1 (Bedroom A), where the schedules are given in percentages; from 12:00 a.m. to 7:00 a.m., the bedroom occupancy is full, while only $50 \%$ of the occupants are present in the bedroom from 7:00 a.m. to 8:00 a.m. A further reduction to $25 \%$ occupancy is observed between 8:00 a.m. and 9:00 a.m. From 9:00 a.m. to 10:00 p.m., the bedroom is left unoccupied; then, by 11:00 p.m., $25 \%$ of the occupants are back, and, between 11:00 p.m. and 12:00 a.m., the bedroom is fully occupied. A similar pattern was used to describe the remaining schedules presented in this work.

For the simulations performed in this work, the Energy Plus simulation engine Version 8.1.0.008 was used. A one-dimensional conduction finite-difference solution algorithm is used in this version. This algorithm was validated in [32] against multiple test suites (analytical verification, comparative testing, and empirical validation); hence, it is suitable for the simulation of real thermal behaviour of PCMs in buildings. In the simulations, the PCMs are consistently positioned to the interior surface of the insulation layer for all structure components. Thus, the wall assembly is made of four different layers, as shown in Table 2 and Figure 4, with PCMs next to the interior wall layer, while the partition walls have a PCM layer on either side of the oriented strand boards (Table 3). The operation of the windows and shading device are presented in Tables 4 and 5. Details of the roof, floor, and external door construction assembly are also illustrated in Tables A1-A3 (Appendix A).

Table 1. Allocation of internal load schedules for every zone.

\begin{tabular}{lllll}
\hline Building Zone & Occupancy & Mechanical Ventilation & Natural Ventilation & Heating \\
\hline Bedroom A & Bedroom schedule 1 & Bedroom schedule 1 & Standard schedule & SH \\
Lounge A & Lounge schedule & Lounge schedule & Standard schedule & SH \\
Kitchen A & Kitchen schedule & Kitchen schedule & Standard schedule & SH \\
Circulation Area A & Circulation schedule & Circulation area schedule & Standard schedule & SH \\
Bathroom A & Bathroom schedule & Bathroom schedule & Standard schedule & BH \\
Storage Room A & No occupancy & No mechanical ventilation & No natural ventilation & NH \\
Bedroom B & Bedroom schedule 2 & Bedroom schedule 2 & Standard schedule & SH \\
Kitchen B & Kitchen schedule & Kitchen schedule & Standard schedule & SH \\
Circulation Area B & Circulation schedule & Circulation area schedule & Standard schedule & SH \\
Bathroom B & Bathroom schedule & Bathroom schedule & Standard schedule & BH \\
Storage room B & No occupancy & No mechanical ventilation & No natural ventilation & NH \\
\hline
\end{tabular}

SH: standard heating, BH: bathroom heating, NH: no heating.

Table 2. Building materials for external wall construction. PCM: phase change material.

\begin{tabular}{|c|c|c|c|c|c|c|}
\hline Layer & Material & $\begin{array}{c}K \\
(W / m \cdot K)\end{array}$ & $\begin{array}{c}\mathrm{C}_{P} \\
(\mathrm{~J} / \mathrm{kg} \cdot \mathrm{K})\end{array}$ & $\begin{array}{c}\rho \\
\left(\mathrm{kg} / \mathrm{m}^{3}\right)\end{array}$ & $\begin{array}{c}\text { Thickness } \\
\text { (m) }\end{array}$ & Solar Absorptance \\
\hline 1 (exterior) & Oriented strand board & 0.105 & 1880 & 650 & 0.0127 & 0.7 \\
\hline 2 & Expanded polystyrene & 0.040 & 1400 & 15 & 0.1910 & 0.6 \\
\hline 3 & PCMs if applicable & & & & $0.003 / 0.0010$ & \\
\hline 1 (interior) & Oriented strand board & 0.105 & 1880 & 650 & 0.0127 & 0.7 \\
\hline
\end{tabular}



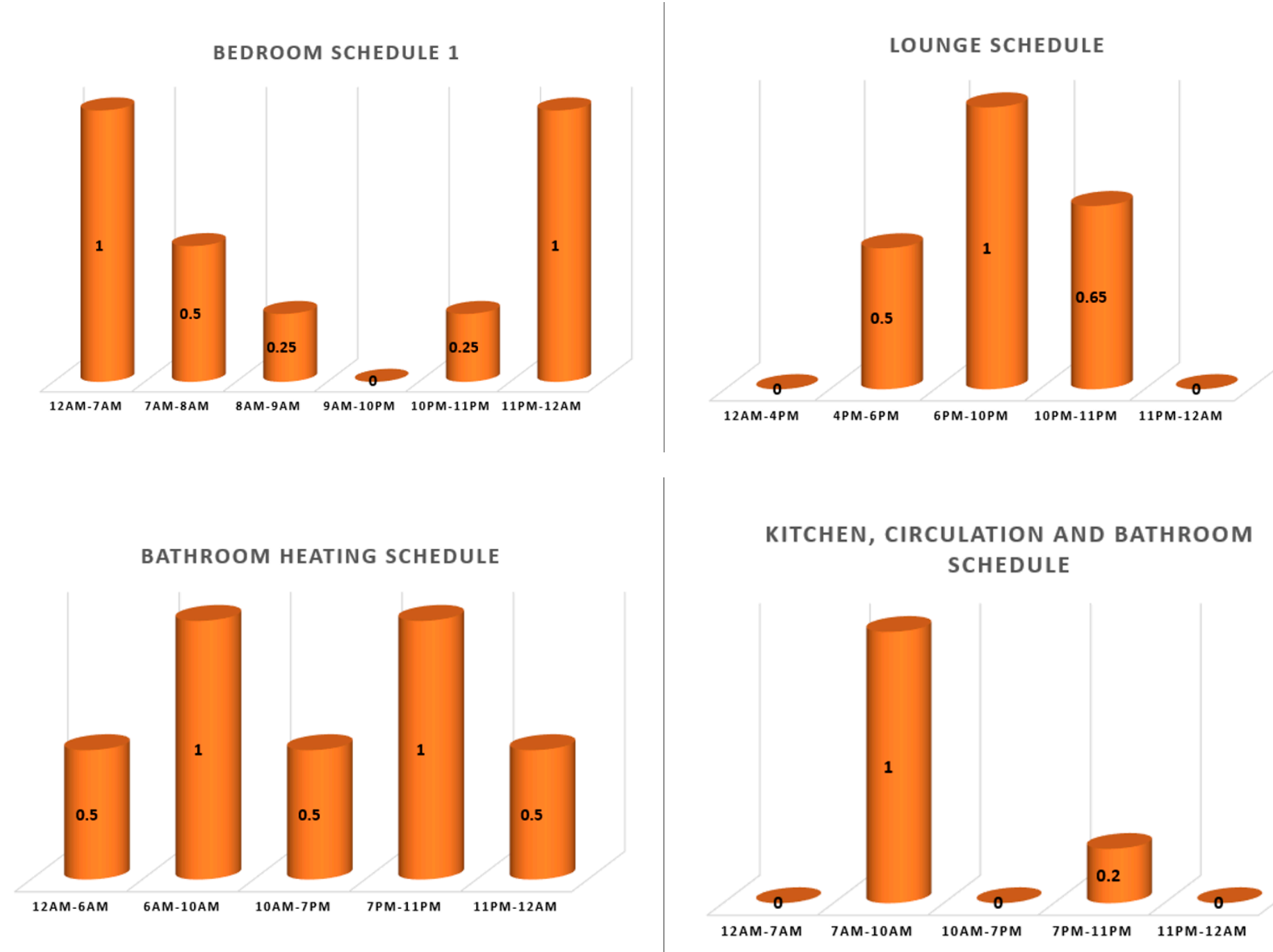

Figure 3. Cont. 


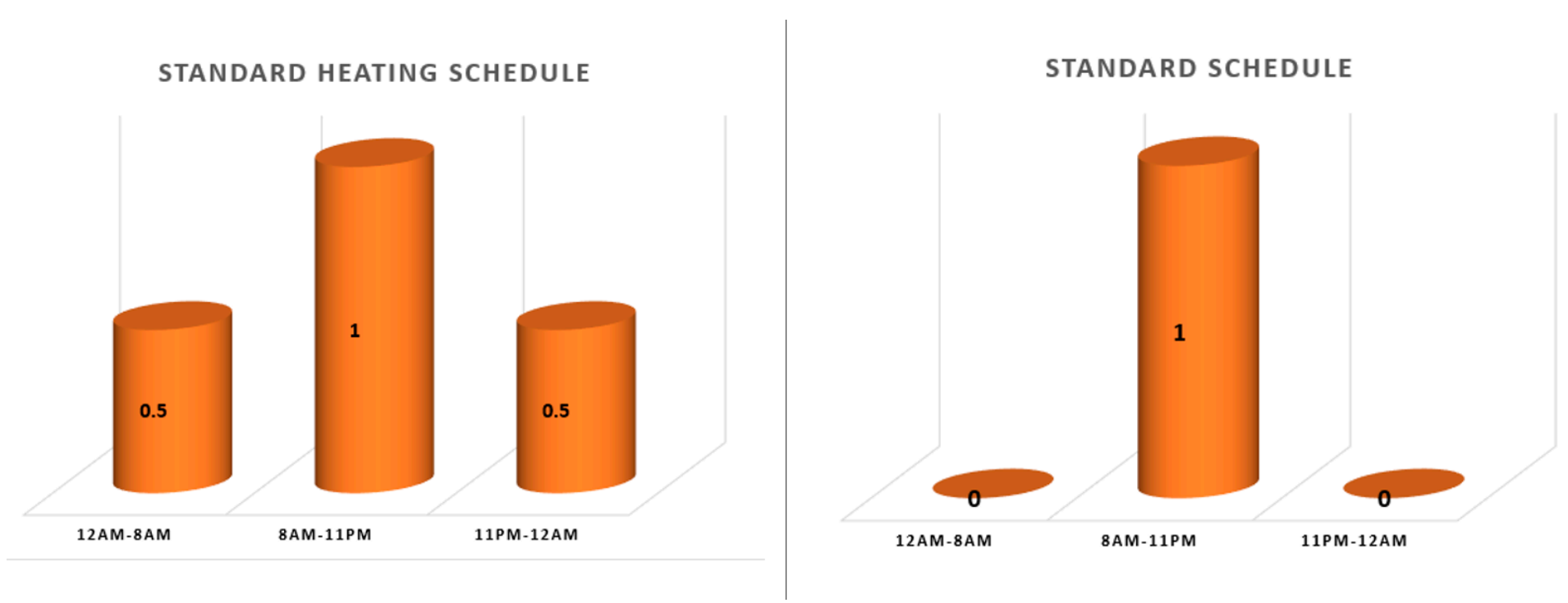

Figure 3. Different daily schedules for buildings A and B. 


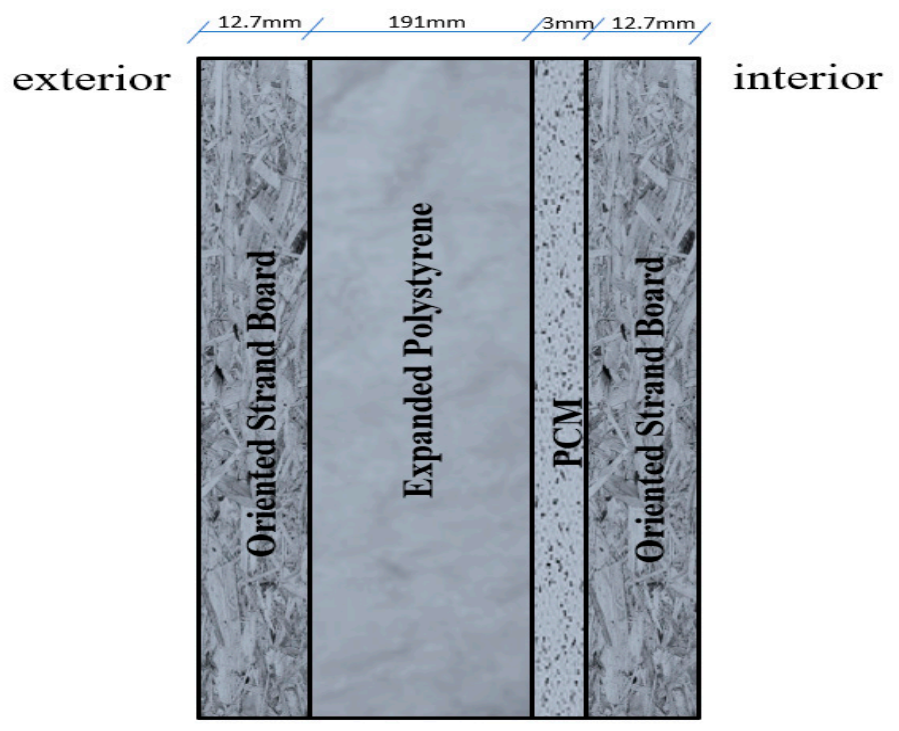

Figure 4. Schematic of the typical external wall (with PCM layer) used in the simulations.

Table 3. Building materials for partition wall construction.

\begin{tabular}{|c|c|c|c|c|c|c|}
\hline Layer & Material & $\begin{array}{c}K \\
(W / \mathrm{m} \cdot K)\end{array}$ & $\begin{array}{c}C_{P} \\
(\mathrm{~J} / \mathrm{kg} \cdot \mathrm{K})\end{array}$ & $\begin{array}{c}\rho \\
\left(\mathrm{kg} / \mathrm{m}^{3}\right)\end{array}$ & $\begin{array}{c}\text { Thickness } \\
\text { (m) }\end{array}$ & Solar Absorptance \\
\hline 1 (exterior) & Oriented strand board & 0.105 & 1880 & 650 & 0.0127 & 0.7 \\
\hline 3 & PCMs if applicable & & & & $0.003 / 0.0010$ & \\
\hline 2 & Expanded polystyrene & 0.040 & 1400 & 15 & 0.1910 & 0.6 \\
\hline 3 & PCMs if applicable & & & & $0.005 / 0.0015$ & \\
\hline 1 (interior) & Oriented strand board & 0.105 & 1880 & 650 & 0.0127 & 0.7 \\
\hline
\end{tabular}

Table 4. Properties of openings.

\begin{tabular}{clccccc}
\hline Layer & \multicolumn{1}{c}{ Material } & $\begin{array}{c}\mathbf{K} \\
(\mathbf{W} / \mathbf{m} \cdot \mathbf{K})\end{array}$ & $\begin{array}{c}\text { Thickness } \\
(\mathbf{m})\end{array}$ & $\begin{array}{c}\text { Solar } \\
\text { Transmittance }\end{array}$ & $\begin{array}{c}\text { Outside Solar } \\
\text { Reflectance }\end{array}$ & $\begin{array}{c}\text { Inside Solar } \\
\text { Reflectance }\end{array}$ \\
\hline 1 & Viracon Norther Low E on clear & 1 & 0.00305 & 0.613 & 0.2 & 0.257 \\
2 & Air & - & 0.013 & - & - & - \\
3 & Drapes_close weave & 0.1 & 0.003 & 0.05 & 0.3 & - \\
\hline
\end{tabular}

Table 5. Frame and dividers.

\begin{tabular}{cccccc}
\hline Layer & U-Value $\left(\mathbf{W} / \mathbf{m}^{\mathbf{2}} \cdot \mathbf{K}\right)$ & Dividers Width $(\mathbf{m})$ & Horizontal Dividers & Vertical Dividers & Frame Width $(\mathbf{m})$ \\
\hline 1 & 3.476 & 0.02 & 1 & 1 & 0.04 \\
\hline
\end{tabular}

\subsection{PCM Selection}

A Mettler Toledo differential scanning calorimeter (DSC) was used to measure the thermo-physical properties of the environmentally friendly PCMs illustrated in Table 6. The heating rate and sample masses used for the DSC were $1^{\circ} \mathrm{C} / \mathrm{min}$ and 4.89 to $6.58 \mathrm{mg}$. The phase change enthalpy of the selected PCMs ranged from $180-203 \mathrm{~kJ} / \mathrm{kg}$, achieved at a peak melting temperature of 18 to $25^{\circ} \mathrm{C}$. 
Table 6. Thermo-physical properties of various organic PCMs.

\begin{tabular}{|c|c|c|c|c|}
\hline PCM & $\begin{array}{c}K \\
(W / \mathbf{m} \cdot K)\end{array}$ & $\begin{array}{c}\mathrm{C}_{\mathrm{P}} \\
(\mathrm{J} / \mathrm{kg} \cdot \mathrm{K})\end{array}$ & $\begin{array}{c}\rho \\
\left(\mathrm{kg} / \mathrm{m}^{3}\right)\end{array}$ & $\begin{array}{l}\Delta H_{s, 1} \\
(k J / k g)\end{array}$ \\
\hline BioPCM mat Q21 & 0.2 & 1970 & 235 & 186 \\
\hline BioPCM mat Q23 & 0.2 & 1970 & 235 & 186 \\
\hline PureTemp 18 & 0.2 & 1740 & 860 & 189 \\
\hline PureTemp 20 & 0.185 & 2110 & 860 & 180 \\
\hline PureTemp 23 & 0.2 & 1915 & 860 & 203 \\
\hline PureTemp 24 & 0.2 & 2945 & 860 & 185 \\
\hline PureTemp 25 & 0.2 & 2140 & 860 & 185 \\
\hline
\end{tabular}

The enthalpy-temperature (H-T) curve is a major characteristic feature of PCMs that helps determine the heat storage capacity. Figure 5 illustrates the $\mathrm{H}-\mathrm{T}$ curve of PT24 at various temperature conditions with the major phase change occurring between 23 and $24^{\circ} \mathrm{C}$.

The design of the PCM sandwich panel previously reported in a study by Marin et al. [32] is similar to the external wall design investigated in this paper. Therefore, it can be expected that a small PCM layer of thickness $(d)=3 \mathrm{~mm}$ would have significant effects on the heating demand of the buildings. In addition, a $10 \mathrm{~mm}$ PCM thickness was also considered in order to determine the maximum effect of PCM on the heating demand and comfort level.

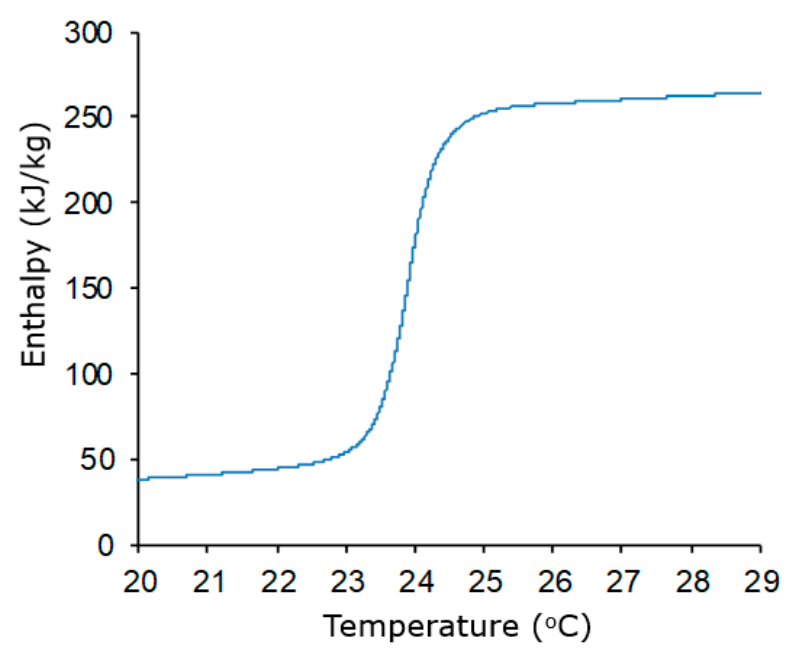

Figure 5. Enthalpy-temperature curve for PT24.

\subsection{Analysis of Energy Performance and Comfort}

The annual heating demand $\left(\mathrm{HD}_{\mathrm{A}}\right)$ and annual discomfort hours $\left(\mathrm{DH}_{\mathrm{A}}\right)$ are important measures of the energy performance and comfort level of a building, and they lead to the definition of strong comparison criteria. The annual energy saving $\left(\mathrm{ES}_{\mathrm{A}}\right)\left(\mathrm{kW}^{\circ} \mathrm{h} / \mathrm{m}^{2}\right)$ and annual comfort enhancement $\left(\mathrm{CE}_{\mathrm{A}}\right)$, measured in hours, are calculated as follows:

$$
\mathrm{ES}_{\mathrm{A}}=\mathrm{HD}_{\mathrm{A} / \mathrm{NoPCM}}-\mathrm{HD}_{\frac{\mathrm{A}}{\mathrm{PCM}}}
$$

and

$$
\mathrm{CE}_{\mathrm{A}}=\mathrm{DH}_{\mathrm{A} / \mathrm{NoPCM}}-\mathrm{DH}_{\frac{\mathrm{A}}{\mathrm{PCM}}} \text {. }
$$

In terms of hourly criteria, Equation (2) can be rewritten as

$$
\mathrm{DR}=\mathrm{DH}=\mathrm{DH}_{\mathrm{NoPCM}}-\mathrm{DH}_{\mathrm{PCM}},
$$


where DR represent the discomfort reduction in hours. As pointed out in Section 2.1, DB enables the display of simulation results at building and zone levels. As such, the obtained $\mathrm{DH}$ results and floor areas for the zones were used to determine building averages. Equation (4) shows the computational method of DB used to calculate building averages weighted by zone floor areas, which is done in this manner for important values like DH and HD.

$$
\mathrm{DH}_{\mathrm{b}}=\frac{\left(\mathrm{DH}_{\mathrm{z} 1} \cdot \mathrm{A}_{\mathrm{z} 1}+\mathrm{DH}_{\mathrm{z} 2} \cdot \mathrm{A}_{\mathrm{z} 2}+\ldots \mathrm{DH}_{\mathrm{zn}} \cdot \mathrm{A}_{\mathrm{zn}}\right)}{\left(\mathrm{A}_{\mathrm{z} 1}+\mathrm{A}_{\mathrm{z} 2}+\ldots+\mathrm{A}_{\mathrm{zn}}\right)}
$$

The discomfort model based on ASHRAE Standard 55-2004 and the Fanger predicted mean vote (Fanger PMV), calculated according to ISO 7730, were used from the generated simulation data to evaluate the comfort level of occupants. As such, the discomfort hour $(\mathrm{DH})$ data are equivalent to the ASHRAE "unmet load hours" [33] and represents "the time when the zone humidity ratio and operative temperature are not in the ASHRAE 55-2004 summer or winter clothes region" [34]. The respective comfort areas for winter and summer clothes are illustrated in Figure 6. Furthermore, for the calculation of the discomfort hours, the occupation of the considered zone was needed so that DHs were not included for times when the room was completely unoccupied.
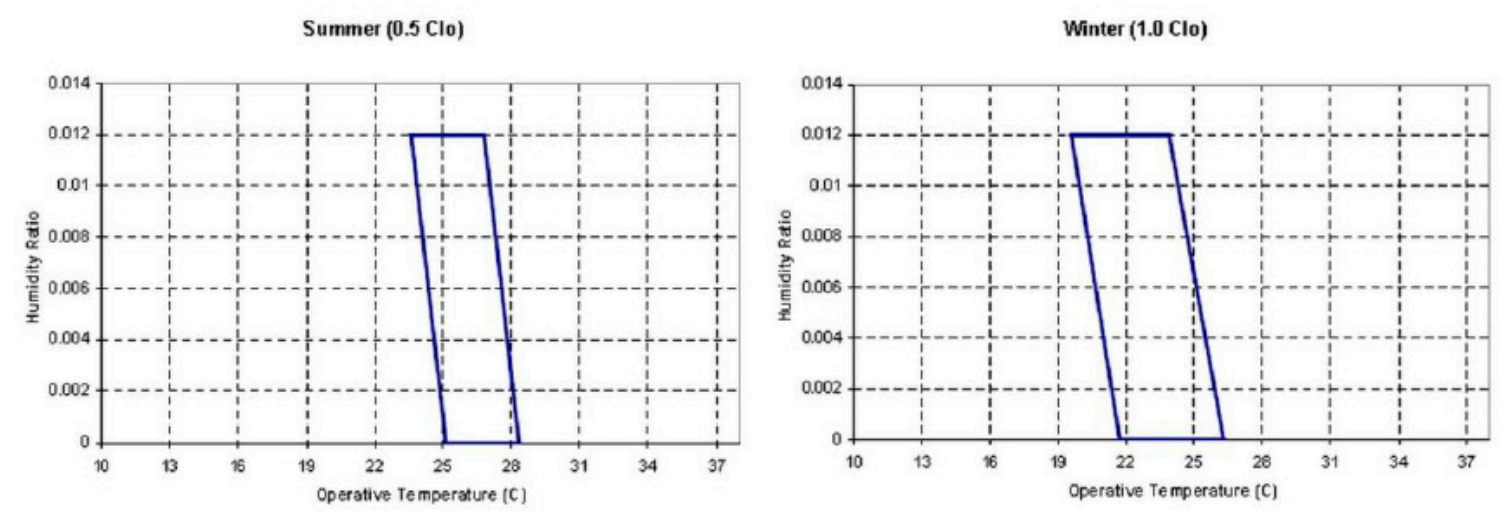

Figure 6. Comfort area (area between blue lines) for summer clothes region (left) and winter clothes region (right) [32].

In general, the following assumptions were made concerning the occupants:

(i) Met: 1 for all occupants (meaning that only men would live at the premises);

(ii) The clothing insulation was assumed to be 1 clo for the winter and 0.5 clo during summer;

(iii) The occupant's activity and calculation of comfort were based on room type.

Simulations were performed for several different building envelopes containing different PCMs or, in some cases, without the application of PCM. To be able to effectively compare the simulation results, five sequences (Seq.) were defined which generally differed in their set temperatures for heating, as shown in Table 7. The variables contained in the sequences were as follows:

(a) The heating setpoint (HSP) indicates the ideal indoor air temperature $\left(T_{A}\right)$ of the zone (or building) when the heating, ventilation, and air conditioning (HVAC) system is turned on.

(b) The heating setback (HSB) defines the minimum $T_{A}$ in a building when the HVAC system is turned off.

(c) When the natural ventilation setpoint (NVSP) is exceeded in a room, natural ventilation (i.e., the opening of windows) is induced provided that the external $T_{A}$ is lower than the internal $T_{A}$ and the respective zone is occupied according to its occupancy schedule.

(d) The shading control temperature (SCT) defines the minimum temperature for the operation of the shading devices. When this temperature is exceeded in an occupied zone, the drapes are closed to reduce further solar gains. 
Table 7. Sequence definition for both buildings: heating setpoint (HSP; ${ }^{\circ} \mathrm{C}$ )/heating setback $\left(\mathrm{HSB} ;{ }^{\circ} \mathrm{C}\right) /$ natural ventilation setpoint $\left(\mathrm{NVSP} ;{ }^{\circ} \mathrm{C}\right) /$ shading control temperature $\left(\mathrm{SCT} ;{ }^{\circ} \mathrm{C}\right)$.

\begin{tabular}{cccccc}
\hline Sequence & Bedroom & Lounge & Kitchen & Circulation & Bathroom \\
\hline 1 & $20 / 18 / 24 / 24$ & $20 / 18 / 24 / 24$ & $20 / 18 / 24 / 24$ & $20 / 18 / 24 / 24$ & $20 / 14 / 24 / 24$ \\
2 & $21 / 19 / 24 / 24$ & $21 / 19 / 24 / 24$ & $21 / 19 / 24 / 24$ & $21 / 19 / 24 / 24$ & $21 / 14 / 24 / 24$ \\
3 & $22 / 20 / 24 / 24$ & $22 / 20 / 24 / 24$ & $22 / 20 / 24 / 24$ & $22 / 20 / 24 / 24$ & $22 / 14 / 24 / 24$ \\
4 & $23 / 21 / 25 / 24.5$ & $23 / 21 / 25 / 24.5$ & $23 / 21 / 25 / 24.5$ & $23 / 21 / 25 / 24.5$ & $23 / 14 / 25 / 24.5$ \\
5 & $24 / 21 / 26 / 25.5$ & $24 / 21 / 26 / 25.5$ & $24 / 21 / 26 / 25.5$ & $24 / 21 / 26 / 25.5$ & $24 / 14 / 26 / 25.5$ \\
\hline
\end{tabular}

A $2{ }^{\circ} \mathrm{C}$ temperature difference $\left(\Delta \mathrm{T}_{\mathrm{NV}}\right)$ between the NVSP and the HSP was defined for all simulations in this paper. Since the heating demand is influenced negatively by a small $\Delta \mathrm{T}_{\mathrm{NV}}$ and the opposite applies to the occupant's comfort, a balance had to be found. According to further simulations with different $\Delta \mathrm{T}_{\mathrm{NV}}$ values, a $\Delta \mathrm{T}_{\mathrm{NV}}$ of $2{ }^{\circ} \mathrm{C}$ represented a good compromise. Apart from PCM thickness and its position, all simulation model sequences of buildings $\mathrm{A}$ and $\mathrm{B}$ were identical.

\section{Results and Discussion}

In this section of the study, an in-depth analysis of the main generated simulation results is presented in terms of the following criteria: the benefit of the application of PCM on an annual scale based on the heating demand and the comfort level within the building, as well as the marginal benefit, the building performance, and the effect of PCM in different locations of the building.

\subsection{PCM Benefit in Annual Simulation}

It was found that there were significant energy saving potentials, as well as a high potential to reduce discomfort, through the application of each type of PCM ( $3 \mathrm{~mm}$ and $10 \mathrm{~mm})$. As expected, there was no identifiable case where one PCM had the most beneficial effects on either comfort or energy saving for every sequence analysed. An increase in PCM thickness had a positive effect on the $E S_{A}$ and $\mathrm{DH}_{\mathrm{A}}$ due to the associated increase in thermal mass of the building envelope when the PCM was used. As discussed later, the limited benefit of using excessive PCM thickness may not be sufficient to compensate for the extra cost associated with the use of a large quantity of PCMs.

\subsubsection{Heating Demand}

The percentage of energy saved due to heating in a PCM-enhanced building in relation to an identical building without PCM gives an indication of the relative annual energy savings $\left(\mathrm{ES}_{\mathrm{A}-\mathrm{Rel}}\right)$. From Equation (1), each PCM model availed a considerable energy-saving potential for both buildings irrespective of sequence or thickness $(d)$. The relative annual energy saving $\left(\mathrm{ES}_{\mathrm{A}-\mathrm{Rel}}\right)$ ranges for buildings $\mathrm{A}$ and B computed from Equation (5) are presented in Tables 8 and 9, respectively.

$$
\mathrm{ES}_{\mathrm{A}-\mathrm{Rel}}=\frac{\mathrm{ES}_{\mathrm{A}}}{\mathrm{HD}_{\mathrm{A} / \mathrm{NoPCM}}} \times 100 .
$$

An overview of the efficiency of PCMs is shown in Tables 8 and 9. The maximum ES $S_{A-R e l}$ values were obtained for the Seq. 1 models. This was mainly due to the definition of the relative annual energy savings since the $\mathrm{HD}_{\mathrm{A} / \mathrm{NoPCM}}$ was quite low for sequence 1 models and, therefore, even small annual energy savings resulted in a high $\left(\mathrm{ES}_{\mathrm{A}-\mathrm{Rel}}\right)$ value. The exact opposite was seen for the total $\mathrm{ES}_{\mathrm{A}}$ values, meaning that the total energy saved tended to rise with increasing sequence numbers for both buildings irrespective of the NV setting.

The lowest $\mathrm{ES}_{\mathrm{A}-\mathrm{Rel}}$ obtained for the PT18 NNV-model with sequence 5 settings (building A, $d=3 \mathrm{~mm}$ ) was $8.38 \%$. This was attributed to the low melting point of the PT18 PCM selected, which was below the HSP and HSB temperatures. However, using a PCM of higher phase transition temperature resulted in better energy savings. As shown in Table 8, using the Q21 PCM NV-model with sequence 1 
settings (building B, $d=10 \mathrm{~mm}$ ), the average energy saving exceeded $30 \%$ and reached an extraordinary value of $71.4 \%$.

Table 8. Relative annual energy savings (\%) for building A with PCM thickness of $3 \mathrm{~mm}$ or $10 \mathrm{~mm}$.

\begin{tabular}{ccccc}
\hline \multirow{2}{*}{ Sequence } & \multicolumn{2}{c}{ Naturally Vented (NV) } & \multicolumn{2}{c}{ Not Naturally Vented (NNV) } \\
\cline { 2 - 5 } & $\boldsymbol{d}=\mathbf{1 0} \mathbf{~} \mathbf{m}$ & $\boldsymbol{d}=\mathbf{3} \mathbf{~} \mathbf{m}$ & $\boldsymbol{d}=\mathbf{1 0} \mathbf{~} \mathbf{m}$ & $\boldsymbol{d}=\mathbf{3} \mathbf{~ m m}$ \\
\hline 1 & $43.45-56.49$ & $30.85-52.26$ & $35.67-50.00$ & $22.77-45.78$ \\
2 & $35.71-54.14$ & $26.22-45.07$ & $29.06-46.94$ & $20.91-37.43$ \\
3 & $29.45-51.81$ & $18.87-44.47$ & $21.96-42.26$ & $14.22-34.45$ \\
4 & $22.65-45.12$ & $12.91-38.63$ & $17.72-37.06$ & $10.58-30.12$ \\
5 & $19.43-38.54$ & $11.25-33.53$ & $13.97-29.55$ & $8.38-24.19$ \\
\hline
\end{tabular}

Table 9. Relative annual energy savings (\%) of building B with PCM thickness of $3 \mathrm{~mm}$ or $10 \mathrm{~mm}$.

\begin{tabular}{ccccc}
\hline \multirow{2}{*}{ Sequence } & \multicolumn{2}{c}{ NV } & \multicolumn{2}{c}{ NNV } \\
\cline { 2 - 5 } & $d=\mathbf{1 0} \mathbf{~ m m}$ & $\boldsymbol{d}=\mathbf{3} \mathbf{~ \mathbf { m }}$ & $\boldsymbol{d}=\mathbf{1 0} \mathbf{~ m m}$ & $\boldsymbol{d}=\mathbf{3} \mathbf{~ m m}$ \\
\hline 1 & $54.47-71.40$ & $51.83-61.77$ & $45.58-64.06$ & $38.62-58.19$ \\
\hline 2 & $41.30-65.89$ & $39.05-55.82$ & $35.65-58.30$ & $33.76-47.15$ \\
\hline 3 & $30.45-57.88$ & $28.55-51.97$ & $26.55-49.72$ & $24.78-40.77$ \\
\hline 4 & $25.59-49.88$ & $23.33-47.17$ & $21.60-42.90$ & $19.87-37.03$ \\
\hline 5 & $23.07-45.03$ & $20.70-44.08$ & $17.46-33.68$ & $16.03-30.53$ \\
\hline
\end{tabular}

On the basis of the more detailed results, it can be stated that, in general, the most efficient PCM for a sequence had a melting range close to the defined heating setpoint. This proves that the beneficial effects are dependent on how well the melting range of the PCM and the HSP match each other.

According to Figure 7, the heating demand for each zone of building B was different. With the use of sequence 2, the most significant influence of PCM was observed for the bedroom and kitchen areas, which had annual energy requirements of less than $10 \mathrm{kWh} / \mathrm{m}^{2}$ for both PT20 and Q21 PCMs. There was only a minor PCM effect for the bathroom zones compared to the building without PCM.

Furthermore, external zones had a higher heating demand than internal zones due to the additional external wall area where a more intense heat transfer took place.

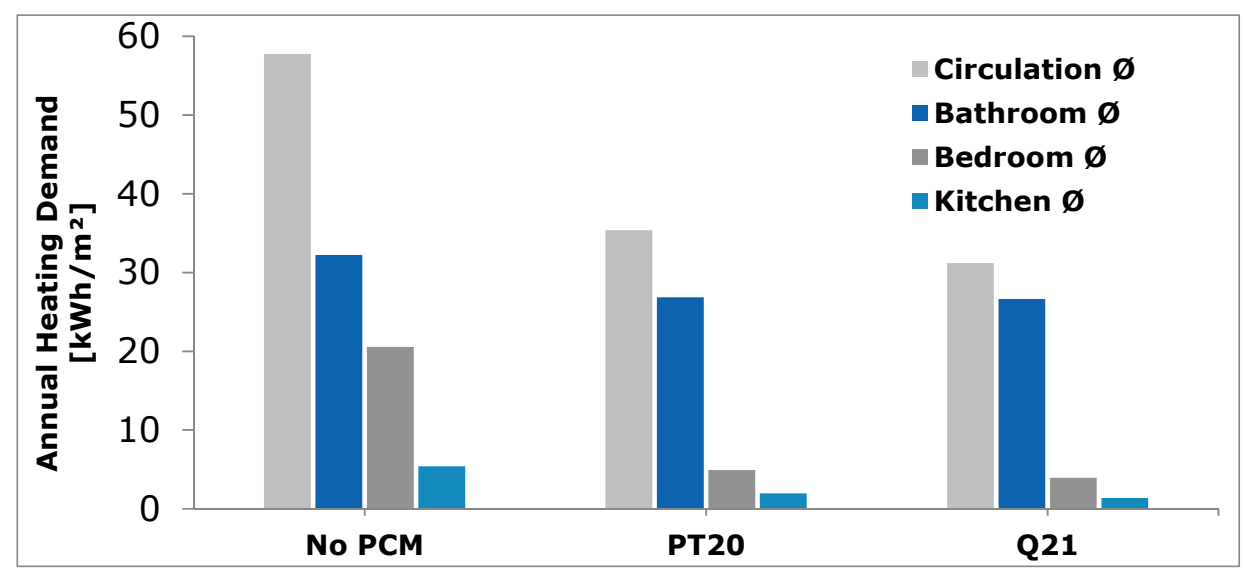

Figure 7. Zonal annual heating demand for NV building B (without PCM and with PCMs of $3 \mathrm{~mm}$ thickness).

The heat exchange between the single residential units was conceivably low as it was assumed that every unit ran with the same temperature setpoints and heating schedules. The poor performance 
of the circulation areas could be traced back to the higher total fresh air values usually present in these zones.

\subsubsection{Comfort}

During summer, the heat gains from solar radiation, air infiltration, and heat conduction can raise the indoor temperatures to an uncomfortably high level (Figure 8). Without the ability to purposely use colder external air for cooling, the internal temperatures can rise even higher. For the analysis of buildings $\mathrm{A}$ and $\mathrm{B}$, the no-PCM and PCM models with and without natural ventilation in conjunction with sequence 4 settings (i.e., Seq. 4; NV/No-PCM, NNV/No-PCM and NV/Q23, NN/VQ23) were chosen for analysis, and the results are presented in Figures 8 and 9, respectively. The BioPCM mat Q23 was selected as it availed the best performance in terms of annual energy savings and discomfort reduction.

The total number of discomfort hours experienced due to indoor overheating was fairly small for naturally vented buildings containing BioPCM mat Q23 (NVQ23), as shown in both Figure 8 (top right). This indicates the ability of the PCM to capture free coolness available at night, which was used to reduce the temperature spikes during the next day. In the absence of natural ventilation (NNVQ23), the melted PCM may not experience full solidification, limiting its ability to release cold heat into the building when needed, as shown in Figures 8 and 9. In such situations, air conditioning is required to assist the solidification process of the PCM, which would come at a cost.

Nevertheless, the lack of thermal mass in the no-PCM models caused higher temperature fluctuations up to $31^{\circ} \mathrm{C}$. Overnight, the temperature was reduced in both no-PCM-models, but only the NV no-PCM model reached temperatures below the HSP of Seq. 4. Hence, the hot water radiators must heat the building in the morning hours before the building naturally heats up through high outside dry-bulb temperature (OUTs), solar gains, etc.

To quantify this, as stated for Fanger PMV models, the overheating DHs must be less than or equal to 200.74 for all NV buildings [31]. The overheating DHs for both buildings were low for naturally vented buildings whether or not PCMs were applied. Nevertheless, the naturally ventilated model without PCM tended to overheat more during summer, which means that natural ventilation is equally important to provide comfort. In comparison with the discomfort caused by reduced temperatures, discomfort due to overheating represented less than one-third of the total annual discomfort hours. In the case of NNV models, this proportion could shift drastically.

To perform a valid comparison between buildings $A$ and $B$, their outermost zones were compared, taking into account that the bedroom zones of building $B$ accounted for the combination of bedroom and lounge in building A. The DH results showed that the occupants of building B experienced more annual DH from overheating, even with higher rates of fresh air changes than the occupants of building A. This situation was valid for most of the models and especially for the no-PCM cases. The reason for this was the occupancy behaviour (or schedule) adopted for building B due to the number of occupants, their metabolic rate, the increased number of indoor equipment, and the higher number of partitions.

In the 2013 addendum to the ASHRAE standard 55, it was explicitly emphasised that the standard does not apply to sleeping occupants as the bed and bedding can provide substantial thermal insulation and occupants may adjust the bedding to suit their personal preferences [23]. The same situation applies to the Fanger PMV model [24]. Consequently, real discomfort may be significantly lower. In fact, according to the ASHRAE handbook for heating, ventilation, and air conditioning applications [35], the insulation values provided by the bed and bedding vary between 0.9 and 4.89 clo. The respective thermal neutral temperatures vary between 30.1 and $8.9^{\circ} \mathrm{C}$. The indoor air temperature of the building with a fixed lower setpoint never dropped below $24^{\circ} \mathrm{C}$ which is why it was assumed that the overnight indoor conditions were not highly uncomfortable in any of the investigated models. Hourly discomfort data for the bedrooms of building A show that around $82 \%$ of the discomfort hours were detected for sleep period (11:00 p.m. to 8:00 a.m.). Generally, the operative temperature never went below $22.2^{\circ} \mathrm{C}$. The analysis of discomfort hour distributions for the bedrooms of building B showed a similar pattern. Thus, the calculated annual discomfort hours could be reduced by $69 \%$ to obtain the real value. 

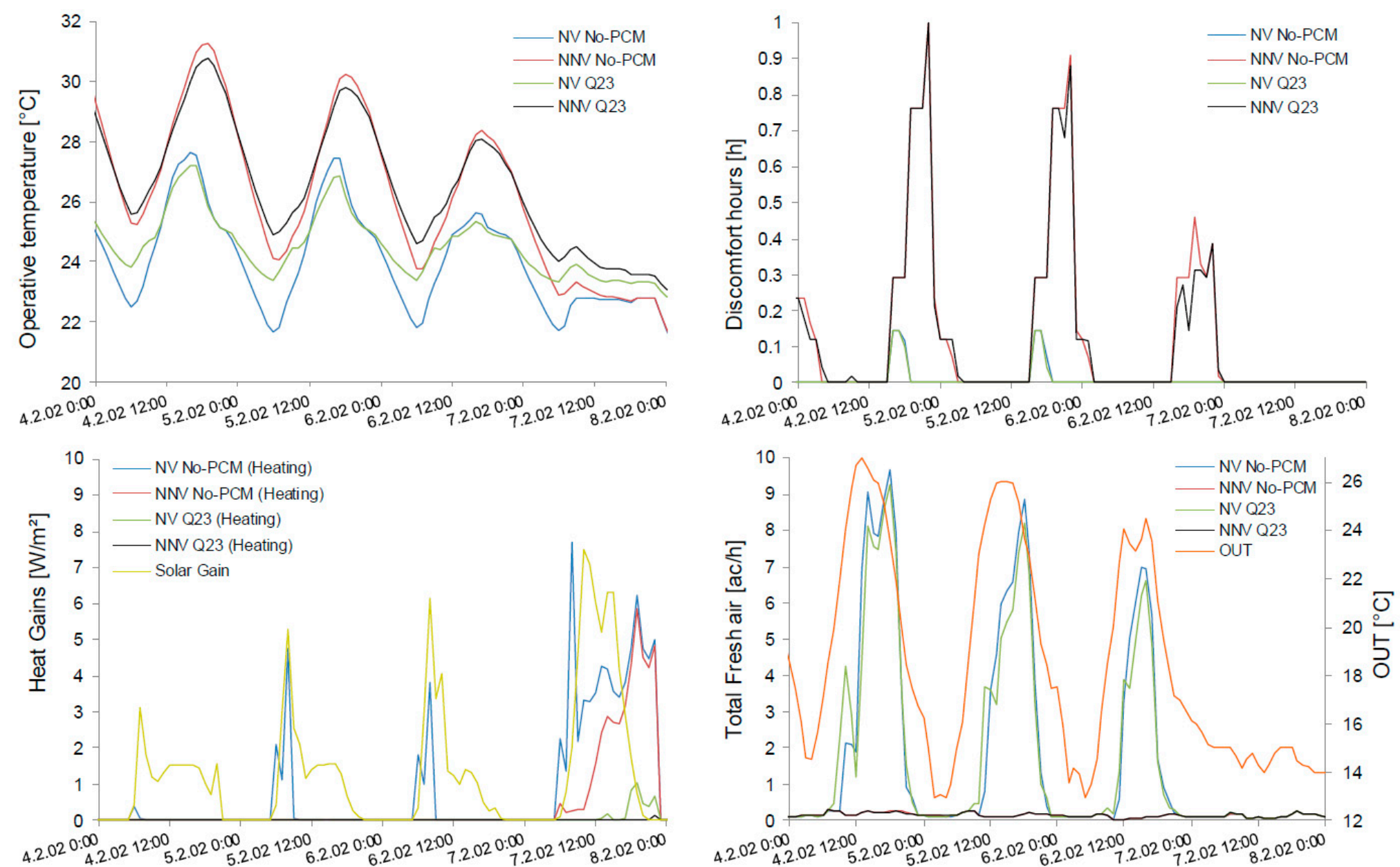

Figure 8. Operative temperature (top left), heat gains (bottom left), discomfort hours (top right), and total fresh air (bottom right) for 4-7 February (summer days) for building A. 

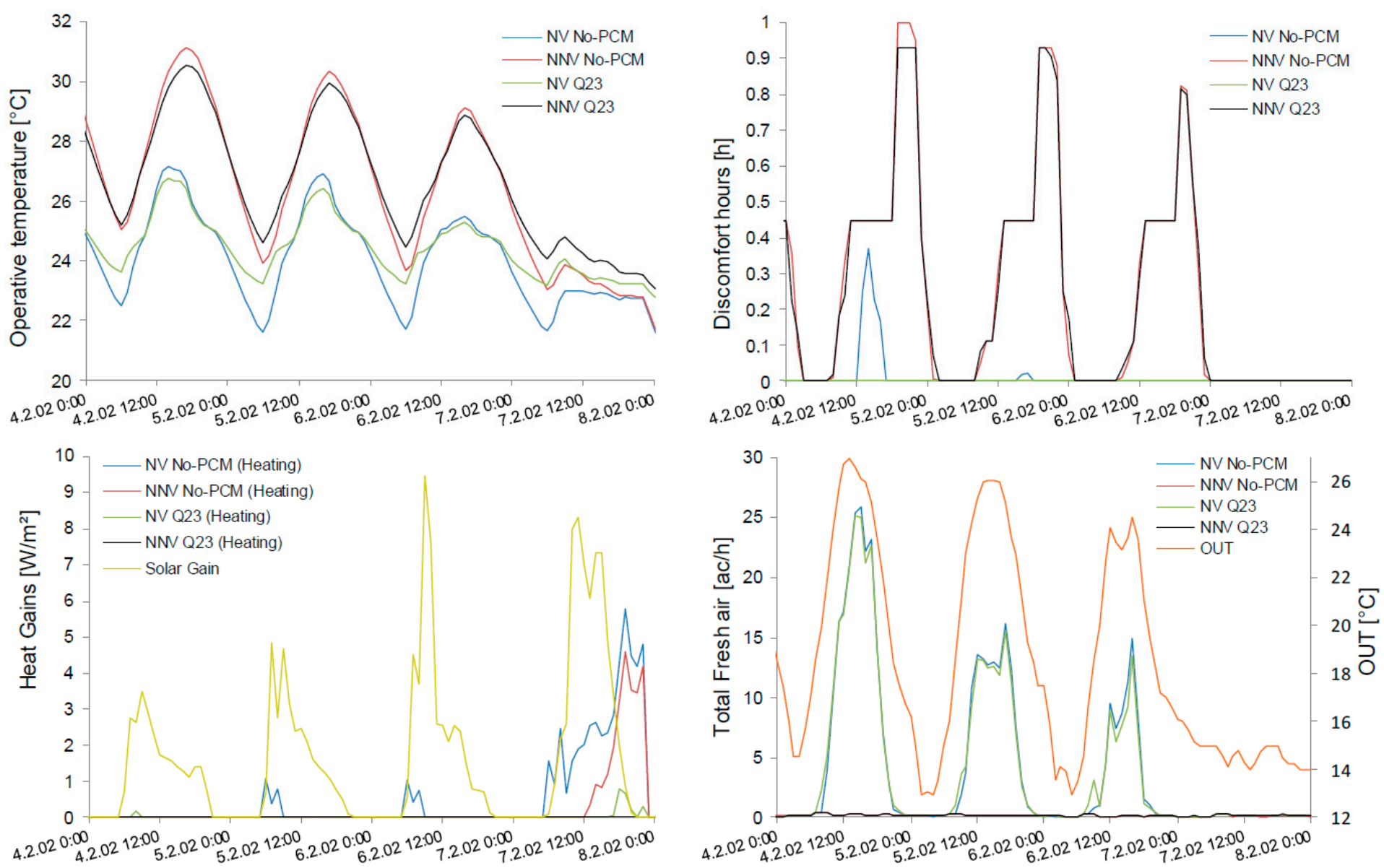

Figure 0-10: 04.02.-08.02. Results for summer days (building 2); from top left to bottom right: OT, DH, HD, TFA \& OUT

Figure 9. Operative temperature (top left), heat gains (bottom left), discomfort hours (top right), and total fresh air (bottom right) for 4-7 February (summer days) for building B. 


\subsection{Marginal PCM Benefit}

When comparing the energy savings and comfort enhancement on an annual basis, due to the application of a particular PCM type of varying thickness, it is striking that the differences were considerably low.

Figure 10 presents the results for the difference between PCM thicknesses of $10 \mathrm{~mm}$ and $3 \mathrm{~mm}$ for building A, where natural ventilation of the building was present. The marginal benefit of each PCM considered in terms of annual heating demand per square metre was analysed when two different $\mathrm{PCM}$ thicknesses were compared (i.e., $\Delta \mathrm{P}=\mathrm{AHD}_{\mathrm{d}=10}-\mathrm{AHD}_{\mathrm{d}=3}$ ). The main differences among the five sequences used were previously described in Section 2.4 (Table 7).

$\square$ Seq. $1 \backsim$ Seq. $2 \backsim$ Seq. $3 \square$ Seq. $4 \quad \square$ Seq. 5

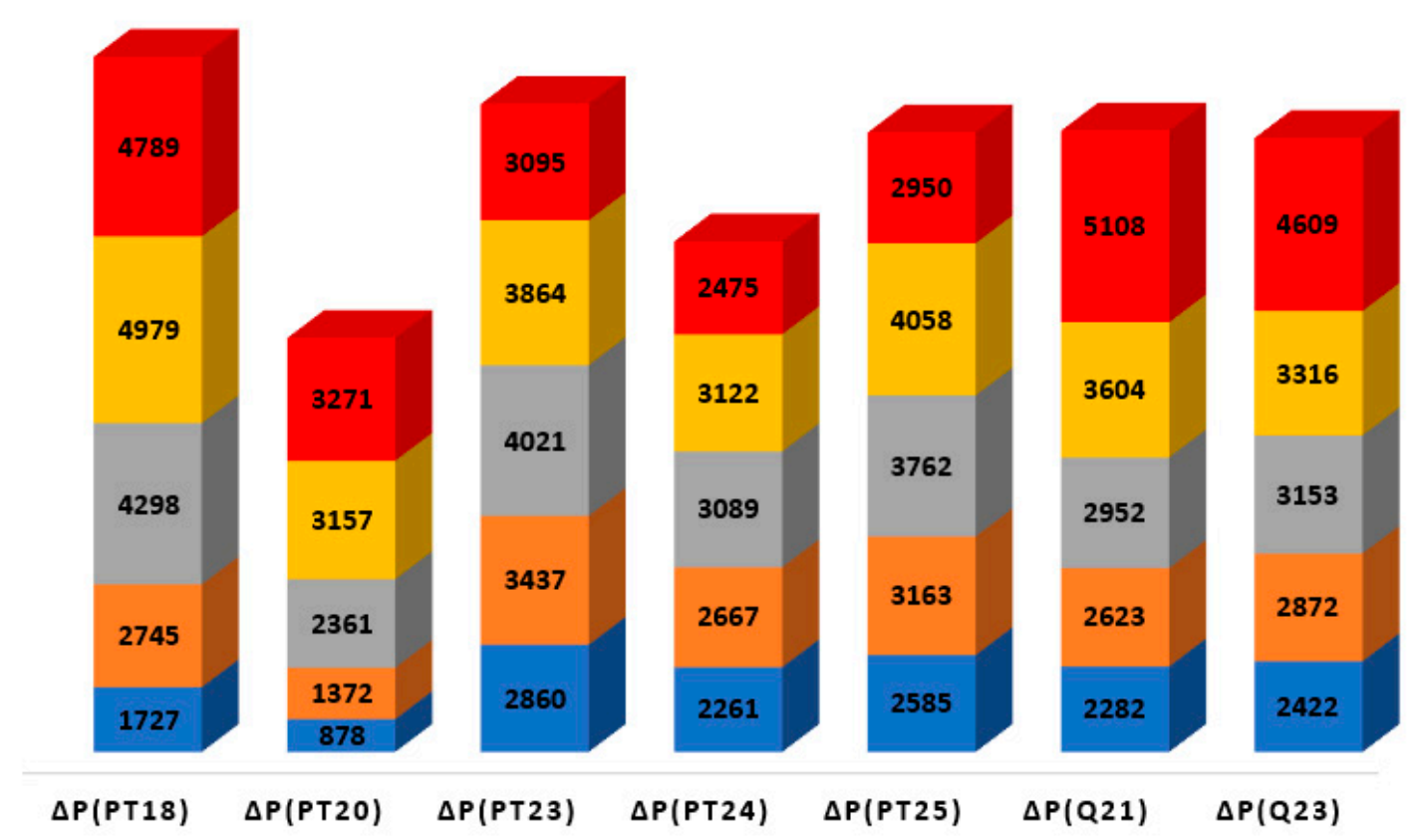

Figure 10. Influence of thickness on annual heating demand for building $A\left(W \cdot h / \mathrm{m}^{2}\right)$.

The marginal benefit per kg PCM reduced with increasing total PCM mass and, thus, increasing layer thickness. That was expected as, for infinitesimally small PCM layers, the storage capacity (enthalpy of fusion) of the PCM could be fully utilised. There is only a limited time frame (e.g., overnight) to release all heat stored in the PCM, i.e., to undergo a full phase change from liquid to solid and vice versa in the daytime. A prerequisite for a complete solidification is that the surface temperatures of the respective structure components are sufficiently lower than the PCM solidification temperature. For instance, with the PT18 PCM, the wall surface temperature must fall below $18^{\circ} \mathrm{C}$ for the liquid PT18 PCM to transition to its solid state. However, through the definition of fairly high heating setback temperatures overnight, the necessary minimum internal surface temperatures could not be attained for most sequences with PT18 and some sequences with PT20 and Q21. Therefore, these PCMs were unable to undergo complete phase change in the summer. Similarly, with increasing PCM thickness, the time needed for a full heat penetration of the whole PCM layer increased [36]. Since the period for the phase change to occur was mainly dependent on weather conditions, it varied considerably. For this reason, the utilization rate of the PCM and the marginal benefit decreased with increasing PCM thickness. 


\subsection{Building Performance}

The ability of the PCM to prevent the building from cooling down fast once the electric heaters operate according to the HSB is the essential quality of the PCM in winter conditions and, thus, for the reduction in annual heating demand. Therefore, the progressions of the operative temperature and heating demand (HD) curves for no-PCM and PCM models are illustrated in Figures 11 and 12 for buildings $\mathrm{A}$ and $\mathrm{B}$ in winter conditions (23-25 June). The operative temperature curves presented a distinct difference between overnight temperatures of the PCM and no-PCM models, showing a significant, positive impact on the calculated comfort. Furthermore, the stored heat released overnight can be seen from the HD curves. The heating demand of the PCM models was considerably smaller overnight and in the morning hours, while it increased slightly in the afternoon and evening periods.
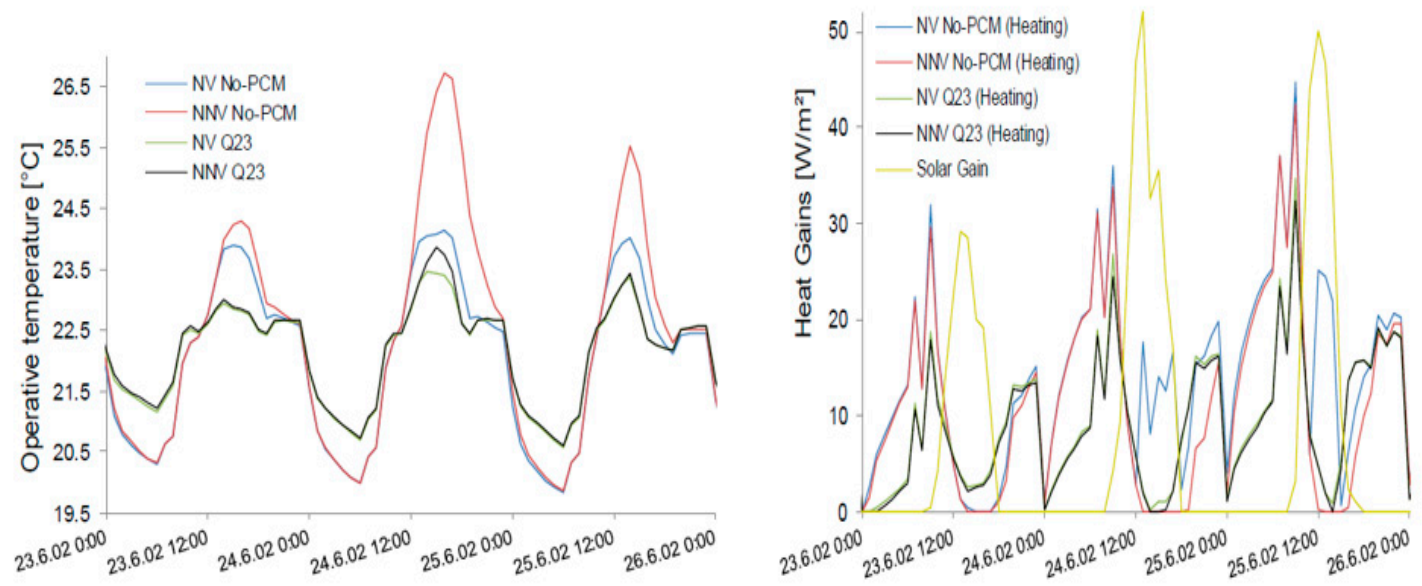

Figure 11. Operative temperature (left) and heat gains (right) for winter days 23-25 June (building A, Seq. 4).
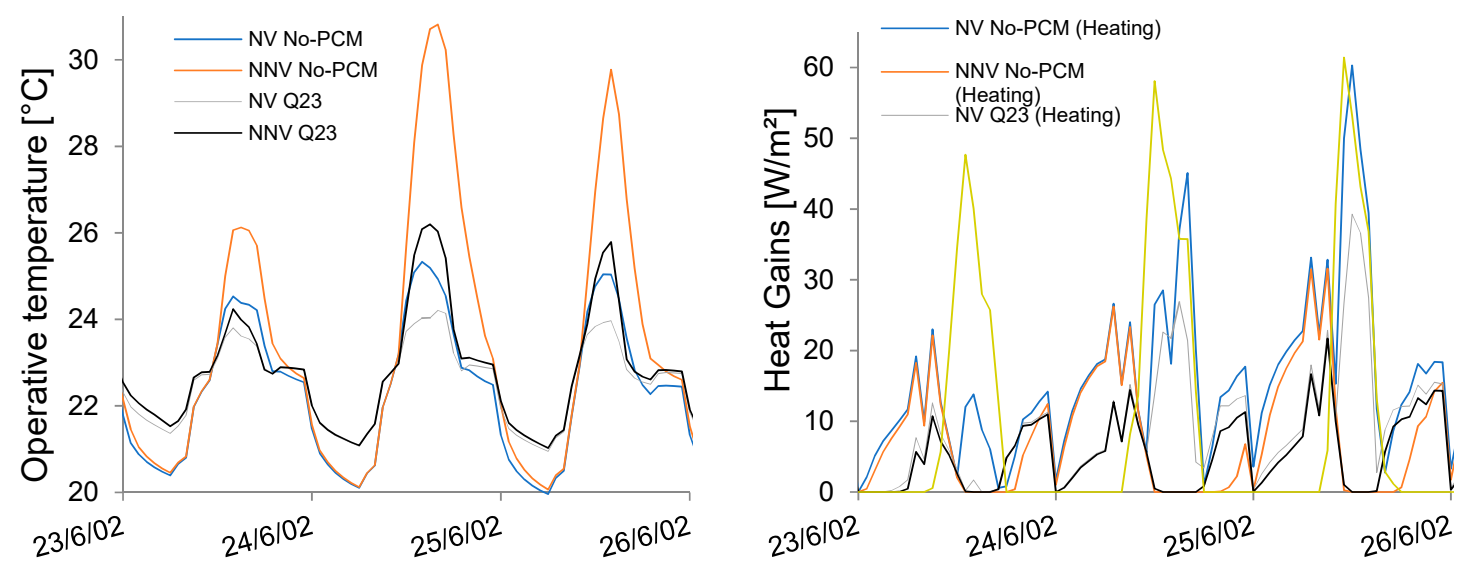

Figure 12. Operative temperature (left) and heat gains (right) for winter days 23-25 June (building B, Seq. 4).

However, from Figures 11 and 12, the diurnal energy savings were still positive by some margin for these days. These positive values resulted from the natural load shifting, which took place due to the increased thermal mass. As the building received large solar gains of up to $61 \mathrm{~W} / \mathrm{m}^{2}$, the excess heat was stored in the PCM, thus reducing overheating of the indoor space. In the morning hours, when the HVAC system operated again according to the HSP, the ambient temperature was already at a higher level. Therefore, less energy was required to reach the HSP, and the building soon after started to receive increasing amounts of solar radiation. Hence, the PCM was mainly "charged" from the solar 
gain, and the stored thermal energy became available overnight when the excess heat was needed. Furthermore, NV was required for the PCM models to avert the overheating in summer conditions previously shown in Figure 8. Although a slight reduction in the maximum indoor temperature could be seen when comparing the two NNV models (one with PCM and the other with no PCM), the drop was by no means sufficient to reach comfortable indoor conditions. As stated earlier, the lack of thermal mass in the no-PCM models resulted in higher indoor temperature fluctuations. Therefore, even in peak summer, heating became continuously necessary in the morning hours for the naturally vented no-PCM models.

\subsection{Effect of PCM in Different Building Locations}

A fraction of the investigated models were altered to demonstrate the respective energy saving potential for each structure component (SC). Due to economic considerations, the layer thickness in each building component was chosen to be $3 \mathrm{~mm}$ (or two layers of $1.5 \mathrm{~mm}$ for the internal partitions). Some of the results for building B are illustrated in Figure 13.

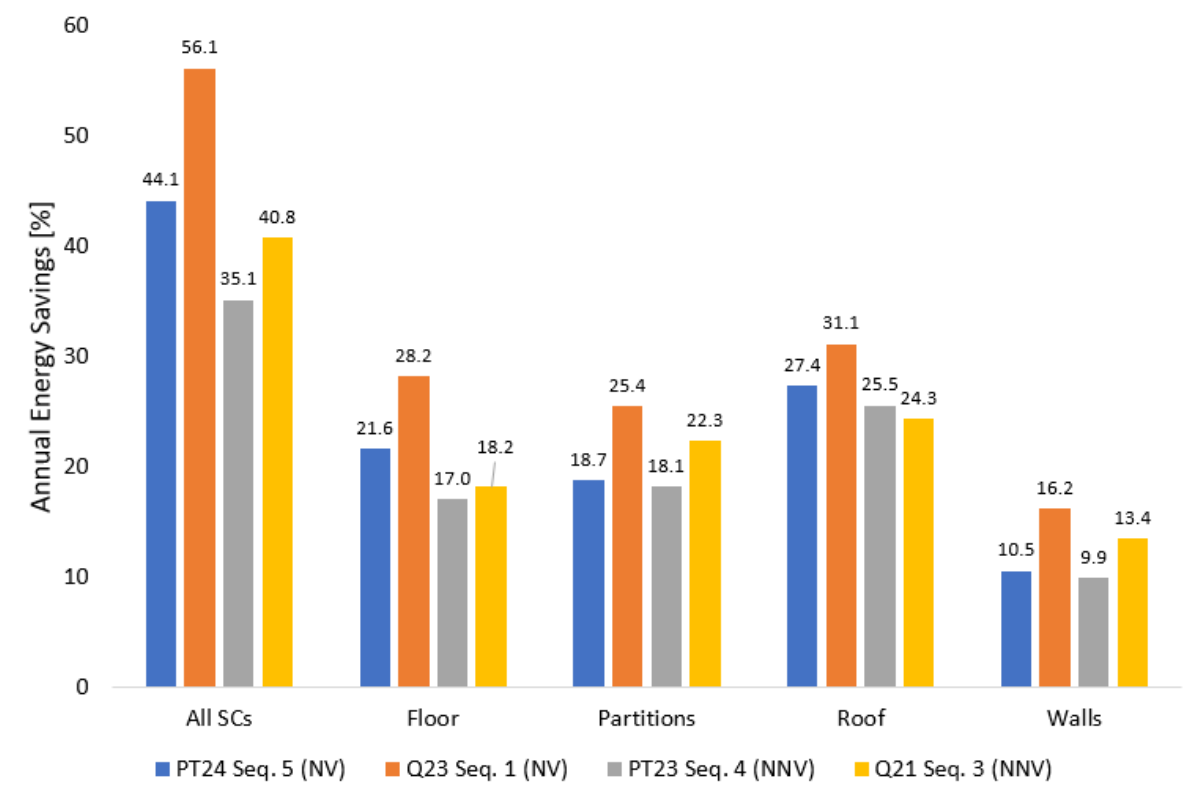

Figure 13. Annual energy savings as a percentage for different equipped surfaces of building B.

From Figure 11, it can be seen that applying PCM on the roof led to the highest annual energy savings when PCMs were only used on one structure component. This applies to building A as well. Although the annual energy savings for the case "all SCs" was considerably higher than that achievable by one single SC, the benefits were still significant. For instance, the maximum savings for a single structure component (roof) reached $11.42 \mathrm{~kW} \cdot \mathrm{h} / \mathrm{m}^{2}$. This is equivalent to a total of $713.75 \mathrm{~kW} \cdot \mathrm{h}$ energy saved per annum for the whole building. Since just over $3600 \mathrm{~kW} \cdot \mathrm{h}$ was consumed per year in the associated no-PCM model, this is a significant saving of over $19 \%$. For building B, the percentage energy saved compared to the no-PCM model was $27 \%$.

In terms of annual comfort enhancement, a distinct pattern could also be observed, indicating that the application of PCMs to the roof had a far more significant impact on the occupant's comfort level than their utilization in other structure components. This was followed by the external walls, the partition walls, and lastly the floor.

Therefore, it is reasonable to normalise the annual energy savings and comfort enhancement as a function of their associated PCM mass, to be able to correctly assess the beneficial effects of the different SCs. Hence, the PCM mass was kept constant among the structure components (building $A=179.24 \mathrm{~kg}$; building $B=323.92 \mathrm{~kg}$ ). The allocation of the resulting thicknesses to their associated structure components was done, as presented in Table 10. 
Table 10. Various PCM thicknesses used in the structure components (SCs) of the building.

\begin{tabular}{ccccc}
\hline Building & Floor $(\mathbf{m m})$ & Partition $(\mathbf{m m})$ & Roof $(\mathbf{m m})$ & External Walls $(\mathbf{m m})$ \\
\hline A & 3.333 & 1.843 & 2.766 & 2.496 \\
B & 2.801 & 1.195 & 2.713 & 5.287 \\
\hline
\end{tabular}

These values of $d$ were implemented in the respective models and, consequently, the specific annual energy savings and comfort enhancement could be evaluated more independently of the PCM mass. The respective specific annual energy savings obtained for building A and B models with constant PCM mass per SC are depicted in Figures 14 and 15.

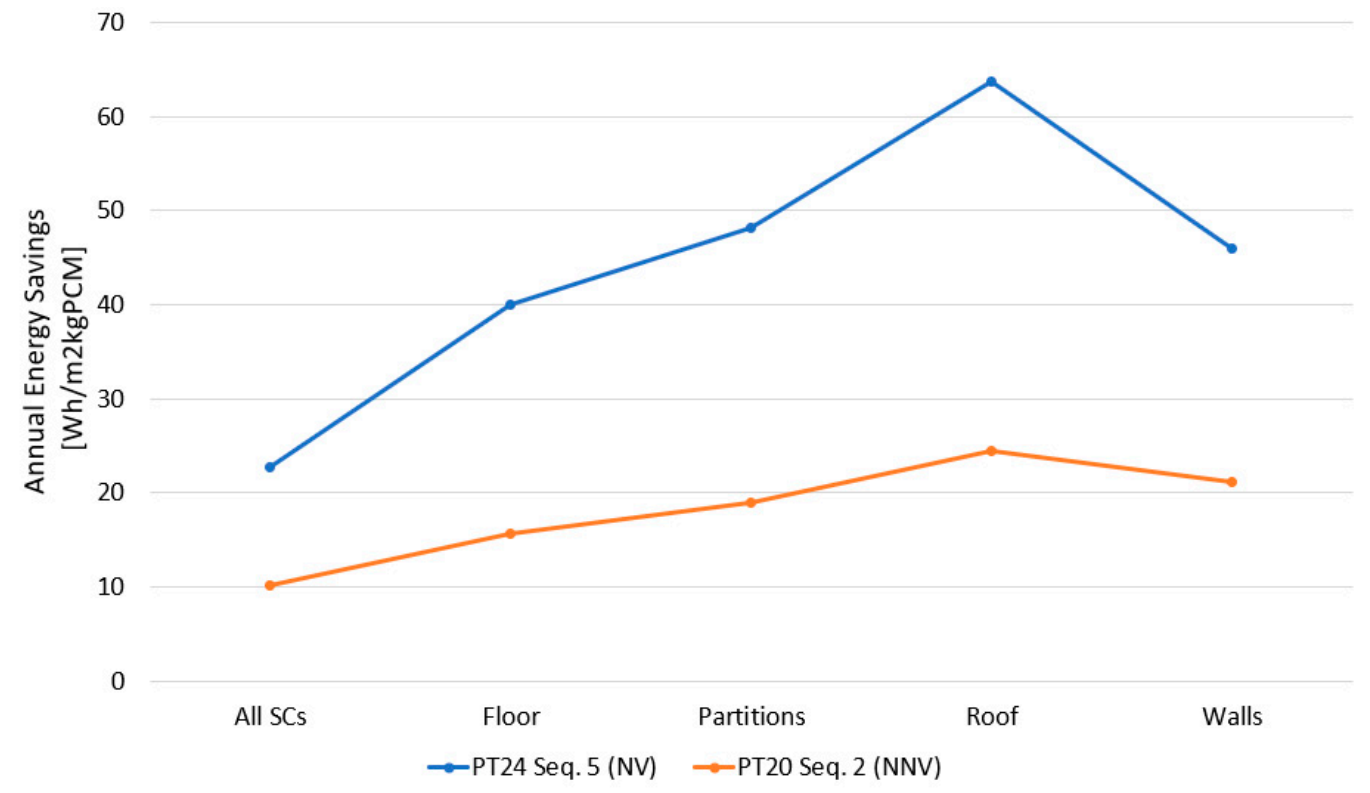

Figure 14. Electricity saving potential per kg PCM for different equipped surfaces of building A.

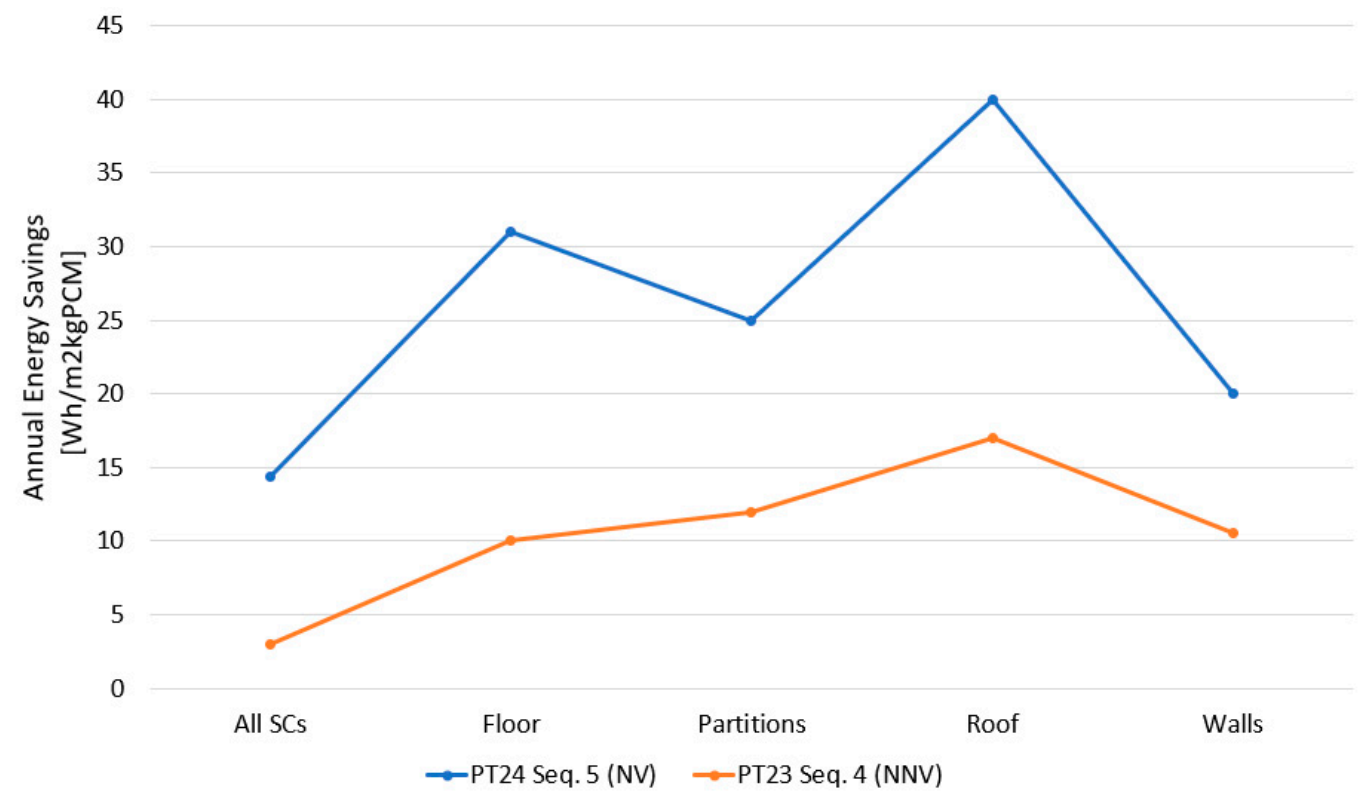

Figure 15. Electricity saving potential per kg PCM for different equipped surfaces of building B. 
The specific annual energy savings and comfort enhancement for the case where PCMs were applied to all building components were consistently lower than those of the individual structural components. This further confirms the findings that every additional $\mathrm{kg}$ of PCM must result in a reduction in marginal benefit.

According to Figures 14 and 15, the roof had the most significant energy-saving potential for both buildings A and B. This may be because, typically, heat flux through the roof appears to be the highest. As such, the PCM acts as a complementary solution to the roof insulation by capturing a copious amount of heat temporarily for future use. However, the second most efficient location in terms of specific energy savings strongly varied among the buildings and the presence of ventilation. Therefore, for building A, it was either the external walls or partitions, and lastly the floor. For building $\mathrm{B}$, the second best location with energy saving potential was the floor due to the natural ventilation effect. In contrast, when natural ventilation was not occurring, the benefit of PCM in the floor was not sufficiently realised. This shows that PCM-enhanced floors should be supported with either natural ventilation or an underfloor heating element [16].

However, as remarked by [1], the main idea should be to place PCMs in surfaces where the highest heat transport is expected (through radiation, conduction, and convection). Thus, for most buildings, the roof is the area where the highest heat transport values can be expected. The roof is exposed to high solar radiation, and air stratification within the building leads to higher heat convection values. Subsequently, the external walls which receive the highest solar gains (northwest and northeast of Christchurch, New Zealand) should be equipped as well [19].

\subsection{Error Analysis}

One of the main uncertainties is the ventilation behaviour of occupants. Only the case where NV was explicitly used to prevent the building from overheating was investigated. The real ventilation behaviour might be very different from this. Occupants would not only open the windows when the building was about to overheat but also as they have varying fresh air requirements. Additionally, the residents are not always in the building for the whole day, meaning that often nobody would be in the building to operate the openings and shading devices. For this reason, preventing the overheating of the building might not work as well in reality as it was assumed in this work. However, at the same time, it must be stated that the heating requirements could be lower as well, since the occupant would not be at home for the whole day. Consequently, the "standard heating" schedule may not be appropriate for the correct assessment of the heating demand.

Liu et al. [15] found that the heat transfer coefficient is significantly increased by the use of PCMs in building walls compared to typical walls, which is due to the higher energy exchange. However, the internal heat transfer coefficients, in numerical studies investigating PCM effects, were usually calculated according to correlations for typical building walls, thus underestimating the real coefficients. The analysis of the internal heat transfer coefficients of the PCM models showed that they varied only little from the internal heat transfer coefficient calculated for the no-PCM walls. Therefore, it can be assumed that the energy-saving potentials in real applications would be higher than the results given in this paper.

\section{Conclusions}

In this paper, the thermal performance of double- and studio- unit lightweight buildings was investigated for the climatic conditions prevailing in the Christchurch region (NZ). The primary purpose of the study was to show the benefits achievable through the application of PCM in these buildings. Therefore, seven different PCMs were investigated. In one case, the study considered the integration of PCM in the whole opaque building envelope and, in other scenarios, the individual structural components of the building were equipped with PCMs.

Substantial energy savings and increased comfort levels were the results of PCM application. Most simulations showed a relative annual energy saving of $30-50 \%$. However, a maximum of $71.4 \%$ 
was observed in one simulation. Generally, it was revealed that a closer melting range to the average room temperature resulted in a higher energy-saving potential. At the same time, several simulations did not confirm this relationship, as PCMs with a less suitable melting range showed the highest energy savings. This led to the conclusion that the results obtained for small test rooms and single walls are not always applicable to more complex buildings.

When only a small PCM mass should be applied, the determination of the most effective surface or structure component is necessary. According to the selected building material composition and the inclusion of PCMs in the roof as a complementary solution in our simulation, the roof provided the highest energy-saving potential for both buildings among all structure components (19-27\% annual energy savings).

In conclusion, the application of PCM distinctly improved the energetic performance and comfort levels of both the double-unit and the studio-unit buildings. Furthermore, temperature fluctuations were reduced throughout the year in Christchurch, which is why the application of PCMs can be recommended.

\section{Recommendations}

Most importantly, further research is essential on the typical behaviour of occupants. Behaviour considerably influences the NVSP, HSP, and SCT and, hence, the heating demand. This could be achieved by conducting a post-occupancy study. Results from this type of quantitative study would be useful for future social housing projects which could significantly improve the prediction accuracy for heating demand.

Author Contributions: E.S. and M.M.F. designed the study. E.S. collected data, performed the numerical analysis and wrote the first draft of the manuscript. C.A.I. and A.A. improved the manuscript and contributed to the interpretation of the results. M.M.F. was involved in planning and supervised the work. All authors discussed the results and commented on the manuscript. All authors have read and agreed to the published version of the manuscript.

Funding: This research received no external funding.

Conflicts of Interest: The authors declare no conflict of interest.

\section{Appendix A}

Table A1. Building materials for roof construction.

\begin{tabular}{|c|c|c|c|c|c|c|}
\hline Layer & Material & $\begin{array}{c}K \\
(W / m \cdot K) \\
\end{array}$ & $\begin{array}{c}\mathrm{C}_{\mathrm{P}} \\
(\mathrm{J} / \mathrm{kg} \cdot \mathrm{K}) \\
\end{array}$ & $\begin{array}{c}\rho \\
\left(\mathrm{kg} / \mathrm{m}^{3}\right) \\
\end{array}$ & $\begin{array}{c}\text { Thickness } \\
\text { (m) }\end{array}$ & $\begin{array}{c}\text { Solar } \\
\text { Absorptance } \\
\end{array}$ \\
\hline 4 (ext) & Lightweight metallic cladding & 0.290 & 1000 & 1250 & 0.0055 & 0.4 \\
\hline 5 & Extruded polystyrene- $-\mathrm{CO}_{2}$ blowing & 0.034 & 1400 & 35 & 0.2000 & 0.6 \\
\hline 3 & PCM if applicable & & & & $0.003 / 0.0010$ & \\
\hline 6 (int) & Roofing felt & 0.190 & 837 & 960 & 0.0050 & 0.8 \\
\hline
\end{tabular}

Table A2. Building materials for floor construction.

\begin{tabular}{clccccc}
\hline \multirow{2}{*}{ Layer } & \multicolumn{1}{c}{ Material } & $\begin{array}{c}\mathbf{K} \\
(\mathbf{W} / \mathbf{m} \cdot \mathbf{K})\end{array}$ & $\begin{array}{c}\mathbf{C}_{\mathbf{P}} \\
(\mathbf{J} / \mathbf{k g} \cdot \mathbf{K})\end{array}$ & $\begin{array}{c}\boldsymbol{\rho} \\
\left(\mathbf{k g} / \mathbf{m}^{3}\right)\end{array}$ & $\begin{array}{c}\text { Thickness } \\
(\mathbf{m})\end{array}$ & $\begin{array}{c}\text { Solar } \\
\text { Absorptance }\end{array}$ \\
\hline 7 (ext) & Plywood (lightweight) & 0.150 & 2500 & 560 & 0.0180 \\
8 & Expanded polystyrene-lightweight & 0.053 & 1400 & 12 & 0.0600 & 0.78 \\
3 & PCM if applicable & & & $0.003 / 0.0010$ \\
9 & Underlay, cork & 0.050 & 1500 & 200 & 0.0029 & 0.6 \\
10 (int) & Timber flooring & 0.140 & 1200 & 650 & 0.0140 & 0.78 \\
\hline
\end{tabular}


Table A3. Building materials for external door construction.

\begin{tabular}{ccccccc}
\hline Layer & Material & $\begin{array}{c}K \\
(\mathbf{W} / \mathbf{m} \cdot \mathbf{K})\end{array}$ & $\begin{array}{c}\mathrm{C}_{\mathbf{P}} \\
(\mathbf{J} / \mathbf{k g} \cdot \mathbf{K})\end{array}$ & $\begin{array}{c}\rho \\
\left(\mathbf{k g} / \mathbf{m}^{3}\right)\end{array}$ & Thickness $(\mathbf{m})$ & Solar Absorptance \\
\hline 11 & Painted oak & 0.190 & 2390 & 700 & 0.0400 & 0.5 \\
\hline
\end{tabular}

\section{Weather Data}

In New Zealand, June to August are the coldest months of the year, while December to February are the hottest months. As shown in Figure A1, the average daytime high outdoor temperature in summer is within $21-23^{\circ} \mathrm{C}$, while that in winter is between 11 and $13^{\circ} \mathrm{C}$.

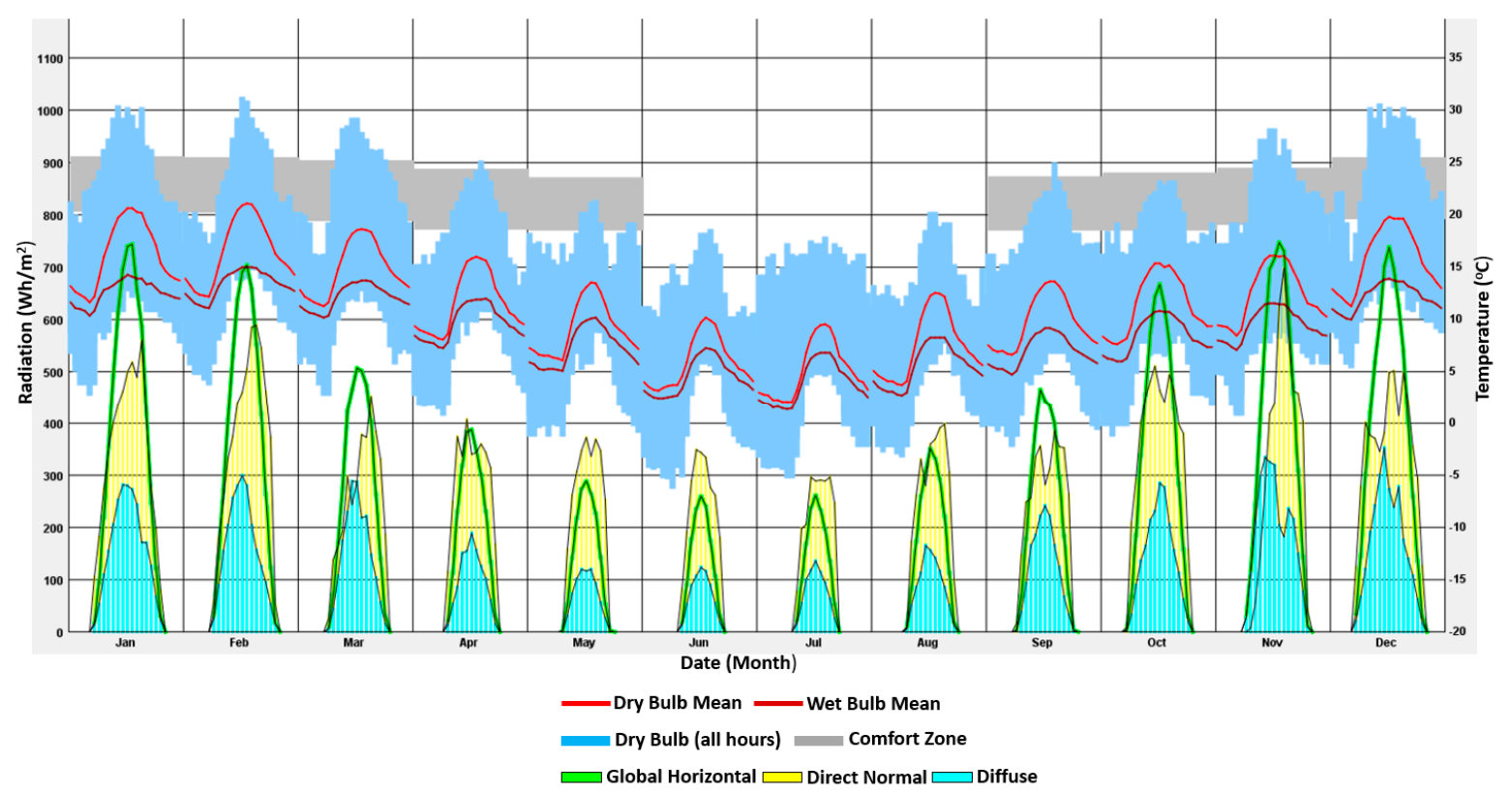

Figure A1. Annual weather data for Christchurch, Canterbury, New Zealand (Adapted from Climate Consultant 6.0).

\section{References}

1. Ikutegbe, C.A.; Farid, M.M. Application of phase change material foam composites in the built environment: A critical review. Renew. Sustain. Energy Rev. 2020, 131, 110008. [CrossRef]

2. Pérez-Lombard, L.; Ortiz, J.; Pout, C. A review on buildings energy consumption information. Energy Build. 2008, 40, 394-398. [CrossRef]

3. Leardini, P.; Iliffe, J.; Gronert, R. Building passive houses in subtropical climates? A lesson learnt from New Zealand. In Proceedings of the 17th International Passive House Conference, Frankfurt, Germany, 19-20 April 2013.

4. Tait, M. Christchurch Earthquake: 100,000 Homes Damaged, 10,000 Unsavable. Available online: https://www.nzherald.co.nz/hawkes-bay-today/news/christchurch-earthquake-100000-homes-damaged10000-unsavable/L7JS7GMGGFVRIVTV42FDUQ7SHU/ (accessed on 20 August 2019).

5. Besen, P.; Leardini, P.; Boarin, P. Passive Houses in New Zealand: A comparison between predicted and real performance through post-occupancy evaluation. In Proceedings of the South Pacific Passive House Conference 2017, Christchurch, New Zealand, 3-5 May 2017.

6. Farid, M.M.; Khudhair, A.M.; Razack, S.A.K.; Al-Hallaj, S. A review on phase change energy storage: Materials and applications. Energy Convers. Manag. 2004, 45, 1597-1615. [CrossRef]

7. Cabeza, L.F.; Castell, A.; Barreneche, C.; De Gracia, A.; Fernández, A.I. Materials used as PCM in thermal energy storage in buildings: A review. Renew. Sustain. Energy Rev. 2011, 15, 1675-1695. [CrossRef] 
8. Zhou, D.; Zhao, C.Y.; Tian, Y. Review on thermal energy storage with phase change materials (PCMs) in building applications. Appl. Energy 2012, 92, 593-605. [CrossRef]

9. Hadorn, J.-C. Thermal Energy Storage for Solar and Low Energy Buildings—State of the Art; Servei de Publicacions de la Universitat de Lleida: Lleida, Spain, 2005.

10. Zalba, B.; Marín, J.M.; Cabeza, L.F.; Mehling, H. Review on thermal energy storage with phase change: Materials, heat transfer analysis and applications. Appl. Therm. Eng. 2003, 23, 251-283. [CrossRef]

11. He, B.; Martin, V.; Setterwall, F. Phase transition temperature ranges and storage density of paraffin wax phase change materials. Energy 2004, 29, 1785-1804. [CrossRef]

12. Sharma, R.K.; Ganesan, P.; Tyagi, V.V.; Metselaar, H.S.C.; Sandaran, S.C. Developments in organic solid-liquid phase change materials and their applications in thermal energy storage. Energy Convers. Manag. 2015, 95, 193-228. [CrossRef]

13. Kuznik, F.; David, D.; Johannes, K.; Roux, J.J. A review on phase change materials integrated in building walls. Renew. Sustain. Energy Rev. 2011, 15, 379-391. [CrossRef]

14. Rathod, M.K.; Banerjee, J. Thermal stability of phase change materials used in latent heat energy storage systems: A review. Renew. Sustain. Energy Rev. 2013, 18, 246-258. [CrossRef]

15. Koschenz, M.; Lehmann, B. Development of a thermally activated ceiling panel with PCM for application in lightweight and retrofitted buildings. Energy Build. 2004, 36, 567-578. [CrossRef]

16. Barzin, R.; Chen, J.J.J.; Young, B.R.; Farid, M.M. Application of PCM underfloor heating in combination with PCM wallboards for space heating using price based control system. Appl. Energy 2015, 148, 39-48. [CrossRef]

17. Gholamibozanjani, G.; Farid, M. A comparison between passive and active PCM systems applied to buildings. Renew. Energy 2020, 162, 112-123. [CrossRef]

18. Gholamibozanjani, G.; Farid, M. Application of an active PCM storage system into a building for heating/cooling load reduction. Energy 2020, 210, 118572. [CrossRef]

19. Kuznik, F.; Virgone, J. Experimental assessment of a phase change material for wall building use. Appl. Energy 2009, 86, 2038-2046. [CrossRef]

20. Errebai, F.B.; Chikh, S.; Derradji, L. Experimental and numerical investigation for improving the thermal performance of a microencapsulated phase change material plasterboard. Energy Convers. Manag. 2018, 174, 309-321. [CrossRef]

21. Kuznik, F.; Virgone, J.; Roux, J.J. Energetic efficiency of room wall containing PCM wallboard: A full-scale experimental investigation. Energy Build. 2008, 40, 148-156. [CrossRef]

22. Omrany, H.; GhaffarianHoseini, A.; GhaffarianHoseini, A.; Raahemifar, K.; Tookey, J. Application of passive wall systems for improving the energy effciency in buildings: A comprehensive review. Renew. Sustain. Energy Rev. 2016, 62, 1252-1269. [CrossRef]

23. Zhu, N.; Ma, Z.; Wang, S. Dynamic characteristics and energy performance of buildings using phase change materials: A review. Energy Convers. Manag. 2009, 50, 3169-3181. [CrossRef]

24. Diarce, G.; Urresti, A.; García-Romero, A.; Delgado, A.; Erkoreka, A.; Escudero, C.; Campus-Celador, Á. Ventilated active façades with PCM. Appl. Energy 2013, 109, 530-537. [CrossRef]

25. Diarce, G.; Campos-Celador, Á.; Martin, K.; Urresti, A.; García-Romero, A.; Sala, J.M. A comparative study of the CFD modeling of a ventilated active façade including phase change materials. Appl. Energy 2014, 126, 307-317. [CrossRef]

26. Mandilaras, I.D.; Kontogeorgos, D.A.; Founti, M.A. A hybrid methodology for the determination of the effective heat capacity of PCM enhanced building components. Renew. Energy 2015, 76, 790-804. [CrossRef]

27. Vautherot, M.; Maréchal, F.; Farid, M.M. Analysis of energy requirements versus comfort levels for the integration of phase change materials in buildings. J Build. Eng. 2015, 1, 53-62. [CrossRef]

28. DesignBuilder. DesignBuilder EnergyPlus Simulation Documentation for DesignBuilder; DesignBuilder: Stroud, UK, 2011; p. 822.

29. Cook, P.; Sproul, A. Towards low-energy retail warehouse building. Archit. Sci. Rev. 2011, 54, $206-214$. [CrossRef]

30. ASHRAE. Thermal Environmental Conditions for Human Occupancy; ANSI/ASHRAE 55-2010; ASHRAE: Washinton, DC, USA, 2010.

31. DesignBuilder. DesignBuilder and Energy Plus Simulation Documentation for DesignBuilder; DesignBuilder: Stroud, UK, 2018; p. 982. 
32. Marín, J.M.; Zalba, B.; Cabeza, L.F.; Mehling, H. Determination of enthalpy-temperature curves of phase change materials with the temperature-history method: Improvement to temperature dependent properties. Meas. Sci. Technol. 2003, 14, 184. [CrossRef]

33. Soares, N.; Gaspar, A.R.; Santos, P.; Costa, J.J. Multi-dimensional optimization of the incorporation of PCM-drywalls in lightweight steel-framed residential buildings in different climates. Energy Build. 2014, 70, 411-421. [CrossRef]

34. Konuklu, Y.; Paksoy, H.Ö. Phase change material sandwich panels for managing solar gain in buildings. J. Sol. Energy Eng. 2009, 131, 41012. [CrossRef]

35. American Society of Heating Refrigerating and Air-Conditioning Engineers, Inc. ASHRAE Handbook-Heating, Ventilating, and Air-Conditioning Applications, SI ed.; American Society of Heating Refrigerating and Air-Conditioning Engineers, Inc.: Washington, DC, USA, 2015.

36. Saffari, M.; De Gracia, A.; Ushak, S.; Cabeza, L.F. Economic impact of integrating PCM as passive system in buildings using Fanger comfort model. Energy Build. 2016, 112, 159-172. [CrossRef]

Publisher's Note: MDPI stays neutral with regard to jurisdictional claims in published maps and institutional affiliations.

(C) 2020 by the authors. Licensee MDPI, Basel, Switzerland. This article is an open access article distributed under the terms and conditions of the Creative Commons Attribution (CC BY) license (http://creativecommons.org/licenses/by/4.0/). 